\title{
Fat and bone: the multiperspective analysis of a close relationship
}

\author{
Maria Pilar Aparisi Gómez ${ }^{1,2}$, Carmen Ayuso Benavent ${ }^{2}$, Paolo Simoni $^{3}$, Francisco Aparisi ${ }^{2}$, \\ Giuseppe Guglielmi ${ }^{4,5}$, Alberto Bazzocchi ${ }^{6}$
}

${ }^{1}$ Department of Radiology, Auckland City Hospital, Auckland, New Zealand; ${ }^{2}$ Department of Radiology, Hospital Vithas Nueve de Octubre, Valencia, Spain; ㄹe ${ }^{4}$ Department of Radiology, University of Foggia, Foggia, Italy; ${ }^{5}$ Department of Radiology, Hospital San Giovanni Rotondo, Foggia, Italy; ${ }^{6}$ Diagnostic and Interventional Radiology, IRCCS Istituto Ortopedico Rizzoli, Bologna, Italy

Correspondence to: Maria Pilar Aparisi Gómez, MBChB, FRANZCR. Department of Radiology, Auckland City Hospital, Auckland District Health Board, 2 Park Road, Grafton, 1023 Auckland, New Zealand; Department of Radiology, Hospital Nueve de Octubre, Calle Valle de la Ballestera, 59, 46015 Valencia, Spain. Email: pilucaparisi@yahoo.es; pilucaparisi193@gmail.com; pilara@adhb.govt.nz.

\begin{abstract}
The study of bone has for many years been focused on the study of its mineralized component, and one of the main objects of study as radiology developed as a medical specialty. The assessment has until recently been almost limited to its role as principal component of the scaffolding of the human body. Bone is a very active tissue, in continuous cross-talk with other organs and systems, with functions that are endocrine and paracrine and that have an important involvement in metabolism, ageing and health in general. Bone is also the continent for the bone marrow, in the form of "yellow marrow" (mainly adipocytes) or "red marrow" (hematopoietic cells and adipocytes). Recently, numerous studies have focused on these adipocytes contained in the bone marrow, often referred to as marrow adipose tissue (MAT). Bone marrow adipocytes do not only work as storage tissue, but are also endocrine and paracrine cells, with the potential to contribute to local bone homeostasis and systemic metabolism. Many metabolic disorders (osteoporosis, obesity, diabetes) have a complex and still not well-established relationship with MAT. The development of imaging methods, in particular the development of cross-sectional imaging has helped us to understand how much more laid beyond our classical way to look at bone. The impact on the mineralized component of bone in some cases (e.g., osteoporosis) is well-established, and has been extensively analyzed and quantified through different radiological methods. The application of advanced magnetic resonance techniques has unlocked the possibility to access the detailed study, characterization and quantification of the bone marrow components in a non-invasive way. In this review, we will address what is the evidence on the physiological role of MAT in normal skeletal health (interaction with the other bone components), during the process of normal aging and in the context of some metabolic disorders, highlighting the role that imaging methods play in helping with quantification and diagnosis.
\end{abstract}

Keywords: Bone marrow; adipose tissue; magnetic resonance spectroscopy (MRS); body composition; osteoporosis

Submitted Oct 28, 2019. Accepted for publication Jan 07, 2020.

doi: 10.21037/qims.2020.01.11

View this article at: http://dx.doi.org/10.21037/qims.2020.01.11

\section{Introduction}

The radiological assessment of bone has for many years been focused on the study of its mineralized component. From the perspective of its involvement in locomotion to the development of pathological conditions, bone was for many years the main object of study as radiology developed as a medical specialty. Bone has been a recurrent topic since the dawn of radiological literature. However, this assessment has until recently been almost limited to its role as principal 
component of the scaffolding of the human body. The development of cross-sectional approach to imaging, with the introduction of computed tomography (CT), gave us a better progressive understanding of how much more laid beyond our classical way to look at bone (1). The arrival of magnetic resonance (MR) unlocked the possibility of direct imaging assessment of the bone marrow, which had been there all along, but almost occult to the eyes of diagnosis.

Today, we know bone is a very active tissue, in continuous cross-talk with other organs and systems, with functions that are endocrine and paracrine and that have an important involvement in metabolism, ageing and health in general.

As a clear example, a tight functional bond has already been demonstrated between bone and muscle. They are considered as a unit when it comes to movement. But beyond this, the connections run deeper, with their development and maintenance mutually modulated, and influenced by normal aging and pathological status (2).

Bone can act as an endocrine organ through factors secreted by osteocytes [e.g., osteocalcin $(\mathrm{OCN})$, transforming growth factor $\beta$, prostaglandin E2] (3), establishing feedback with organs like the kidney, but also with muscle, which is also a secretory organ, with a regulatory function through factors that are secreted by muscle cells (e.g., myostatin, irisin, $\beta$-aminoisobutyric acid). Interestingly enough, some aspects of the endocrine interaction between bone and muscle appear to be regulated by load (4).

Bone is also the continent for the bone marrow. Bone marrow fills the "gaps" in the trabecular bone, and has the form of "yellow marrow" (mainly adipocytes) or "red marrow" (hematopoietic cells and adipocytes). Recently, numerous studies have focused on these adipocytes contained in the bone marrow, often referred to as marrow adipose tissue (MAT). There is evidence that the bone marrow adipocytes do not only work as storage tissue, but are also endocrine and paracrine cells, with the potential to contribute to local (bone homeostasis and also hematopoiesis) and systemic metabolism.

In this sense, MAT plays a role in bone health, through its interaction with the other components of bone. Many metabolic disorders (osteoporosis, obesity, diabetes) have a complex and still not well-established relationship with bone health (5), and just as they relate to the mineralized component of bone, they have links to MAT. Their impact on the mineralized component of bone is well-established, and analyzed and quantified through different radiological diagnostic methods $(1,6)$.

The purpose of this work is to review the evidence linking MAT to metabolic disorders with an impact on bone health, highlighting the role that imaging methods play in helping with quantification and diagnosis. The review will briefly address what is the evidence on the physiological role of MAT in normal skeletal health (interaction with the other bone components), during the process of normal aging and in the context of pathological bone status.

\section{Anatomy of the bone marrow fat}

\section{Origin and distribution}

In adults, approximately $85 \%$ of the adipose tissue in the body is "white" (unilocular white adipocytes that store lipids) and is located in subcutaneous or visceral deposits. Approximately $10 \%$ of adipose tissue is "brown" (multilocular adipocytes with numerous mitochondria) and has a role in energy balance, through the production of heat in response to cold stress (7).

MAT makes up to $5 \%$ to $10 \%$ of fat mass in adults (approximately $2.6 \mathrm{~kg}$ in an adult) $(8,9)$.

And to complicate matters, MAT has surface markers that make it distinctive and different from purely white or brown adipose tissue - what is called a "beige phenotype"and represents a combination of both cell types (10).

Adipocytes represent approximately $45 \%$ of the red bone marrow (hematopoietic), and up to $90 \%$ of the yellow marrow.

During skeletal maturation, yellow marrow progresses and red marrow involutes, this is known as the process of conversion. Yellow marrow is already advancing in newborns, visible in their phalanges, to practically be present in the whole skeleton by the third decade of life. Conversion happens from appendicular to axial skeleton, and within the long bones, from diaphysis to metaphysis. In adults, yellow bone marrow is mainly located in the appendicular skeleton.

The number of adipocytes in the bone marrow gradually increases during skeletal growth, but also during ageing. This process is parallel to metabolic processes in the bone, but while there is an increase of bone mass during growth and sexual maturation, there is bone loss and decline in sexual hormone activity with ageing.

Bone marrow adipocytes do not group in lobules as it happens in other fat depots. They are contained, scattered in the hematopoietic tissue. At around $50 \mu$ they are smaller than the adipocytes in the subcutaneous or visceral fat (11).

A couple of decades ago the notion that marrow adipocytes had the same mesenchymal precursor as osteoblasts was 


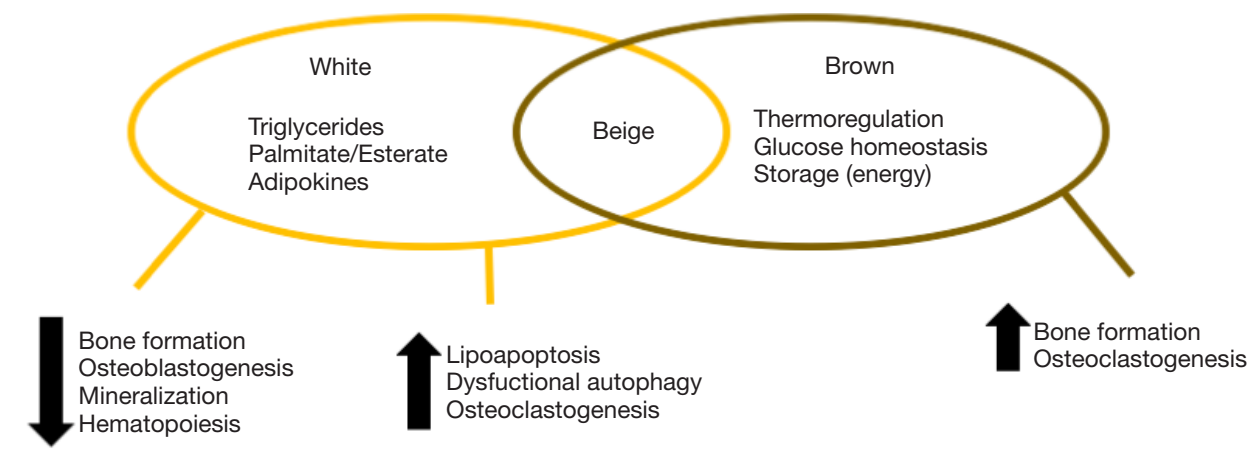

Figure 1 Representation of the combined roles of bone marrow fat. White-like phenotype characteristics reduce bone formation and hematopoiesis, with an increase in adipogenesis and bone destruction. Brown-like phenotype stimulates bone formation and osteoblastogenesis.

introduced (12). Based on this, an initial hypothesis on the relationship between fat and bone was formulated, inversely relating adipocyte and osteoblast differentiation.

The idea gradually evolved to the current hypothesis that MAT is a heterogeneous tissue, with adipocytes that have different origins, some of them related to osteoblasts (13), extramedullary adipocytes or from common progenitor that will develop into a final phenotype depending on location, which will determine their function (9). So, according to this, this heterogeneous character of MAT translates on different effects on bone that can be positive or negative for bone homeostasis.

Only a few years ago, two types of MAT were described in rodents (14). These differences were noted based on spatial location, but soon they realized that cellular morphology and fatty acid composition were different. The time in which they started to develop was also different. Constitutive MAT (cMAT) appears early (1-4 weeks) is found in the distal tibia, contains large adipocytes and is primarily composed of unsaturated lipids (UL).

Regulated MAT (rMAT) appears later (12 weeks), is found in the proximal tibia (but also femur and lumbar vertebrae), contains hematopoietic marrow and is composed of saturated lipids (SL).

The fact that the lipid composition is different suggests different functions. It has been seen that rMAT responds to cold exposure with a decrease in volume, and to caloric restriction with an increase in volume, as well as ageing and pathophysiological processes-and cMAT does not. All this could suggest that MAT varies with skeletal location. For example, in the proximal tibia, adipocytes of rMAT may be supportive of bone remodeling, releasing energy and secreting adipokines, whereas in the distal tibia, where remodeling is much less active, adipocytes may be more quiescent, or have a negative effect on bone turnover (15). However, it is still unclear whether this could be due to other factors, such as temperature or blood perfusion and some studies consider this two-type classification too simplistic, based on the behavior of MAT in some pathophysiological conditions. Extrapolation to humans is complex, given the relative proportion of MAT in rodents is lower and skeletal maturation is different (16).

\section{Functions and regulation}

\section{Paracrine and endocrine function}

Fat is distributed in the body in deposits that serve different purposes, including storing and releasing energy. With the discovery that extramedullary adipocytes produce hormones (adipokines), adipose tissue has acquired an endocrine status. These adipokines exert a regulatory action in systemic metabolism (17).

In the same way as adipocytes of other origins, bone marrow adipocytes are secretory cells, with the possibility to release adipokines in their microenvironment, thus exerting an autocrine and paracrine function: fat and bone are capable of mutual regulation (18).

As previously described, MAT has a combined phenotype, combination of white and brown adipose tissue, considered a "beige phenotype" (10). As such, it will manifest the good and bad characteristics of each kind of fat (Figure 1). An interesting hypothesis is that the beneficial role of each one of these components may be impaired by age or the development of conditions. For example, with aging or diabetes, marrow fat seems to lose expression 
of the brown-like phenotype, with a decreased in energy metabolism and thermogenic response. Similarly, with aging or osteoporosis, the bone marrow environment becomes more toxic (generalized steatosis, lipoapoptosis, lipotoxicity) than other deposits, which is typical feature of a white-type phenotype (19).

Osteoblasts and adipocytes share a common precursor. The activation of the peroxisome proliferator-activated receptor (PPAR $\gamma)$ gene in bone marrow stem cells favors adipogenesis, while it inhibits osteoblastogenesis, moreover, it has been recently described that the activation of this particular gene promotes osteoclast differentiation, and thus bone resorption (20). The fact that in bone these different cells (adipocytes, osteoblasts, osteocytes) exist together and may vary in population in physiological and pathological conditions suggest that their fates are interconnected through mechanisms of homeostasis.

Marrow adipogenesis is regulated through many pathways. For example, high levels of growth hormone favor bone tissue differentiation, as opposed to adipocytic tissue (21). High levels of insulin-like growth factor 1 (IGF1) have the same effect (22). Glucocorticoids have been demonstrated to act in the opposite way, inducing marrow adiposity (21). Parathyroid hormone has been demonstrated to support bone tissue differentiation (23).

Also, interestingly, it has been demonstrated that an increase in an osteocyte secreted glycoprotein, sclerostin (secreted in situations of increased mechanical stress), correlates with high amounts of MAT in men and inhibition of osteoblastic bone formation, which means that bone tissue itself also has a regulating effect on marrow adipogenesis $(24,25)$. This knowledge has opened up new ways for treatment of osteoporosis, through the development of blocking agents (26).

Adipocytes secret different products, amongst them adipokines, forkhead box protein $\mathrm{C} 2$ (FOX C2), Wnt signaling proteins, IGFs, bone morphogenetic protein (BMP), monocyte chemoattractant protein 1 (MCP-1), uncoupling protein 1 (UCP1), preadipocyte factor 1 (Pref-1) and inflammatory factors (9).

Amongst the adipokines the most important are adiponectin and leptin. Adiponectin secreted by MAT acts in an anti-osteogenic manner, blocking osteoblast proliferation in the short-term, through a paracrine mechanism in the bone microenvironment (27). But besides from the paracrine effect in the bone environment, adiponectin also has an endocrine effect. As a consequence, the long-term effect of increased adiponectin levels is different, based on the decrease in the sympathetic tone in osteoblasts (this involves central signaling mechanisms in the brain) and favors an increase in bone mass and decrease in MAT (28). Other fat deposits also secret adiponectin (white adipose tissue) and this will have a systemic effect but also an effect on bone homeostasis, hence the negative correlation established between visceral adipose tissue (VAT) and bone density (29), for example.

Leptin is the other main adipokine secreted by MAT, which has a general role in the regulation of fertility, appetite and energy metabolism (27). MAT demonstrates high expression of this protein, and osteoblasts show an elevated number of receptors for it, which suggests its important paracrine role in bone homeostasis (10). In bone, leptin has a positive effect on osteogenesis, increasing bone mineral density (BMD), and a negative effect on adipogenesis, decreasing the number and size of adipocytes (21). When leptin concentrations are high systemically the effects are different. Through its hypothalamic activity (appetite regulation), sympathetic tone is increased and marrow adipogenesis, with an increase in size and number of marrow adipocytes, is favored over osteogenesis.

These complex effects of MAT on the bone component will indirectly modulate its endocrine functions. As an example, bone is involved in the homeostasis of glucose in the body (30). Insulin secreted by the pancreas can bind with osteoblasts, and suppress the expression of osteoprotegerin (OPG), which is a protein that inhibits the differentiation of osteoclasts (and therefore increases bone resorption). The degradation of bone results in changes in $\mathrm{pH}$ that trigger changes (decarboxylation) in a protein secreted by osteoblasts, OCN. This decarboxylated OCN promotes insulin secretion and increases insulin sensitivity in the liver, muscle and deposits of fat deposits (31).

Adipocytes have been also demonstrated to play a role in the homeostasis of the hematopoietic microenvironment (32) with a negative effect, through the release of inhibitors of hematopoiesis and leukocytogenesis.

Paracrine factors secreted by MAT can inhibit B lymphopoiesis, compromising the proliferation and maturation of lymphoid progenitors (33). B and T cells produce OPG, which plays a role in the coordination of osteoclast bone resorption and osteoblast bone formation. The inhibition of lymphopoiesis means a decrease in OPG levels, which results in an imbalance leading to excessive osteolytic activity (34).

Moreover, B and T lymphocytes have receptors for leptin, which means this adipokine is involved in immune 
response. Leptin enhances T lymphocyte response, which through an inflammatory cascade results in increased osteoclastic activity, and therefore has a negative effect on bone metabolism (35).

To summarize, increased levels of bone marrow fat translate into changes in the bone microenvironment, which has a modulation effect on osteoblastogenesis, osteoblast function, mineralization, bone resorption and hematopoiesis. The modulation of these processes will eventually cascade to have local and systemic effects on bone and general metabolism through many interconnected pathways.

\section{Mechanical implications}

Amongst the functions of bone, a very important one as the main component of the scaffolding of the human body is to counter the effect of physical loads. Naturally, the bone marrow contained in bones will play a very important role on the biomechanics.

Bone marrow fat is an important component of loadbearing subchondral bone, filling in the compartments between the elastic bony trabeculae.

The study of the mechanical properties of bone has classically been focused on the trabecular scaffold. When stress studies are performed in vitro, the typical specimen would remain intact when the loading force causes up to $5 \%$ strain (reduction to $95 \%$ of its height by the load), bouncing back to its full height when the load is removed. Once the load applied causes a higher strain the deformity becomes permanent. In in vitro testing, the maximal loads used oscillate around $2 \mathrm{MPa}$ (36). However, loading pressures in vivo, while performing normal activities (standing up or climbing stairs) have been found to be as high as $18 \mathrm{MPa}$ (37). This supports the idea that there is an important in vivo component added to the function of trabeculae as scaffolding, and is the presence of bone marrow within the bone, mainly fatty marrow (38).

In addition, a recent study performed by Pansini et al. (39) using MR spectroscopy to measure fat contents in the femoral head found that there was no significant variation over the decades between 20 and 60 years of age, which points towards the idea that the functionality of fat in this location remains constant throughout most of our lives, and has to do with joint biomechanics.

The mechanical environment of bone marrow can be defined by its hydrostatic pressure, fluid-flow induced shear stress and viscosity (40). Hydrostatic pressure in the bone marrow is approximately one fourth of systemic blood pressure, and remains constant as long as the mean value does not drop beyond $81 \mathrm{mmHg}$ (41). Viscosity is a critical parameter modulating the shear stresses experienced by the trabecular surfaces due to vibratory loads, and is the factor that will be more influenced by the type of bone marrow present, with fatty marrow being generally considered less viscous than hematopoietic marrow. In humans, fatty marrow viscosity has only been measured in the calcaneus (42). There is limited information on the literature of the density of bone marrow fat, which is comparable to density of fat tissue (40).

Recently, marrow fat has been consolidated as a shock distributor. Simkin (43) explains the potential mechanisms of marrow behavior during loading of the subchondral bone through two models, and "open" and a "closed" one.

The trabecular bone is a porous and elastic tissue, which is formed by the trabecular scaffolding (containing strong elastic type 1 collagen fibers) and the viscous fluid it contains, the bone marrow.

In the open model the marrow fat and water are assumed to flow freely between compartments as the bone is compressed, and therefore only the walls (trabeculae) will bear the compression stress. It is important to mention that most studies support the open model (44). In the closed model, there is no free transit of fat or water, because the viscosity of fat does not allow it to pass through trabecular pores. The volume of fat marrow in the compartments remains constant and the compression causes bulging of the walls. In this way, the force of impact is transformed by the presence of marrow fat into tensile stress throughout the walls, which contain type 1 collagen fibers. This means the transformation of a loading force into tensile forces, that dissipate in a descending pressure gradient (Figure 2). This explains the "shock absorbance".

The current trend is to consider the two models: a closed, perfect shock absorbing model for young joints, with development of an open model as bone structure changes (more fenestration, greater pores) with age or pathological conditions $(45,46)$. This will lead to change in the way the subchondral bone reacts to loading, with more load taken by the already weakened trabeculae and risk of injury at lower loads $(46,47)$.

In the context of bone disease, aging or disuse, the mechanical properties of bone marrow change. In vitro experiments have demonstrated that the resident mesenchymal stem and progenitor cells respond to variations in the hydrostatic pressure, fluid shear or changes in viscosity. As a result, the changes in mechanical microenvironment also play a role in the homeostasis of bone (40). 


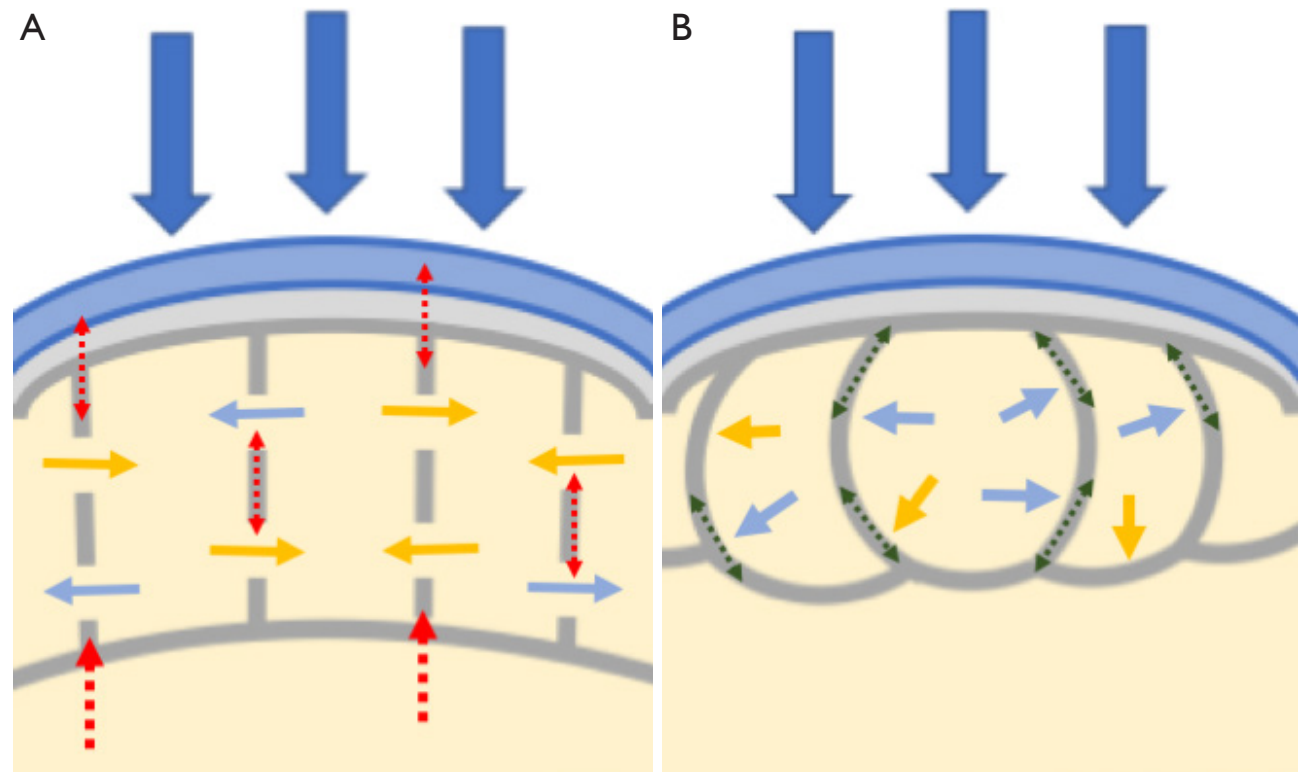

Figure 2 Mechanisms of marrow behavior during loading of the subchondral bone. (A) Diagram representing the open model. The marrow fat (yellow arrows) and water (blue arrows) are assumed to flow freely through pores between compartments as the bone is compressed, and therefore only the walls (trabeculae) will bear the compression stress (red dotted arrows). (B) Diagram representing the closed model. In the closed model, there is no free transit of fat or water (yellow and blue arrows respectively), because the viscosity of fat does not allow it to pass through trabecular pores. The volume of fat marrow in the compartments remains constant and the compression causes bulging of the walls. This means the transformation of a loading force into tensile forces (green dotted arrows), that dissipate in a descending pressure gradient.

\section{Imaging based quantification of bone marrow fat}

\section{$M R$}

Several MR techniques have been developed to assess the bone marrow composition with MR. Studies have investigated different sites in the skeleton (pelvis, long bones) but the most frequently assessed location is the spine (vertebral bone marrow).

\section{T1-weighted imaging}

T1 imaging is the simplest way of assessment of fat content in the bone marrow. Bone marrow fat can be measured by applying thresholds (intensity of subcutaneous adipose tissue) to extract bone marrow fat voxels (48).

A study by Shen et al. (49) investigated intra- and interobserver reproducibility for the assessment of bone marrow fat in T1 weighted images. The coefficient of variation (CV) was $0.9 \%$ for intraobserver and $2.2 \%$ for interobserver, and concluded that the main source of error for assessment of bone marrow fat in T1-weighted imaging were the partial volume effects and the incorrect threshold selection of regions that would contain red marrow.
Only a few years ago, a system of scoring similar to the one used with dual-energy X-ray absorptiometry (DXA) was suggested by an Italian group (50).

\section{Magnetic resonance spectroscopy (MRS)}

The current gold standard for bone marrow fat quantification is proton MRS (1H-MRS). Most of the recent clinical research on the relation between MAT and BMD have used this method to separate water and fat signals.

The main types of sequences used are point-resolved spectroscopy (PRESS) and stimulated echo acquisition mode (STEAM) single-voxel 1H-MRS sequences. Perfusion sequences can be added to study MAT perfusion (51). These sequences can be applied to the pelvis, spine and hip. The most frequent location is the spine (Figure 3).

$1 \mathrm{H}-\mathrm{MRS}$ can also be used to measure lipid saturation within the fatty marrow (the ultimate composition of MAT, based on the presence and type of hydrogen bindings). The spectrum that results shows peaks for water, SL, UL and residual lipids (RL) (52) (Figure 4).

To asses vertebral MAT, a single or several vertebral bodies are used (L1-L4). A single voxel is placed in 
A
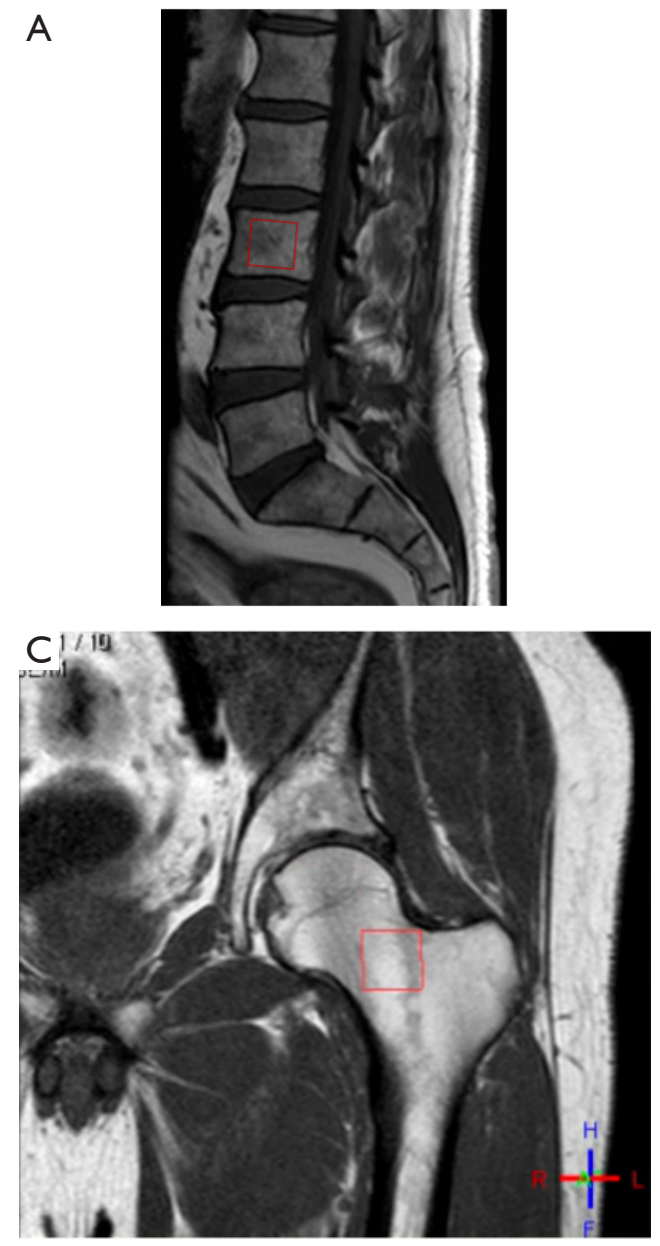

B
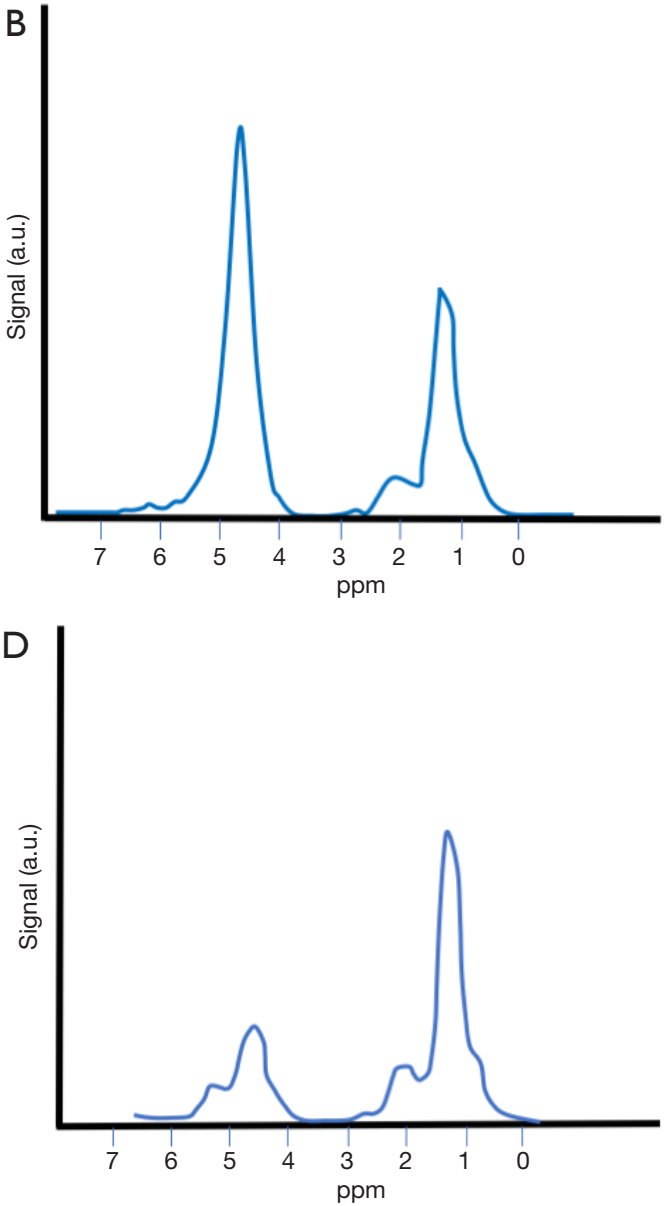

Figure 3 Difference in the spectral curve between spine and hip. Fifty-four-year-old male. (A) Voxel placed in the body of L3 (red box); (B) the spectral curve shows abundant water (strong water peak) in comparison to lipids. Conversion into fatty marrow happens from appendicular to axial skeleton, and within the long bones, from diaphysis to metaphysis. In adults, yellow bone marrow is mainly located in the appendicular skeleton. When there is a strong water peak, the extraction of the spectrum of unsaturated lipids will be challenging; (C) same patient, voxel placed in the femoral neck (red box); (D) lipids peak is stronger in this location.

the centre of the vertebral body (53). In $1 \mathrm{H}-\mathrm{MRS}$ measurements, fat content is expressed as a percentage, called bone marrow fat fraction (BMFF). This percentage is calculated using the large lipid peak at 1.3 parts per million (ppm), which are the SL, normally disregarding the smaller lipid peaks at 2.0 and $5.3 \mathrm{ppm}$, which correspond to RL and UL (53). The resulting formula is: fat content $(\%)=$ [signal amplitude (I) fat/(I fat + I water) $\times 100$. If the three peaks are considered, the formula results in fat content $(\%)=[($ ISL + IRL + IUL)/(ISL + IRL + IUL + I water) $] \times 100(54)$.

The degree of saturation can be obtained too, expressed as indexes: unsaturation index (UI) as UL $(\%)=[$ IUL/(ISL
+ IRL + IUL) $] \times 100$, and saturation index as SL $(\%)=[$ ISL/ $(\mathrm{ISL}+\mathrm{IRL}+\mathrm{IUL})] \times 100$.

The CV of vertebral BMFF has been reported to be from $1.7 \%$ (same day, repositioning) (55) to $12.3 \%$ with a standard deviation (SD) of 0.10 for reproducibility after 6 months (56).

A frequent problem in studies using $1 \mathrm{H}-\mathrm{MRS}$ is that the difference in $\mathrm{T} 2$ relaxation times between the water and fat components may not be accounted for, and measured as a signal-weighted fat fraction at a single echo time (TE), which depends on the used TE and field strength. To solve this problem, the proton density fat fraction (PDFF) can be obtained, by performing a multi-TE MRS 


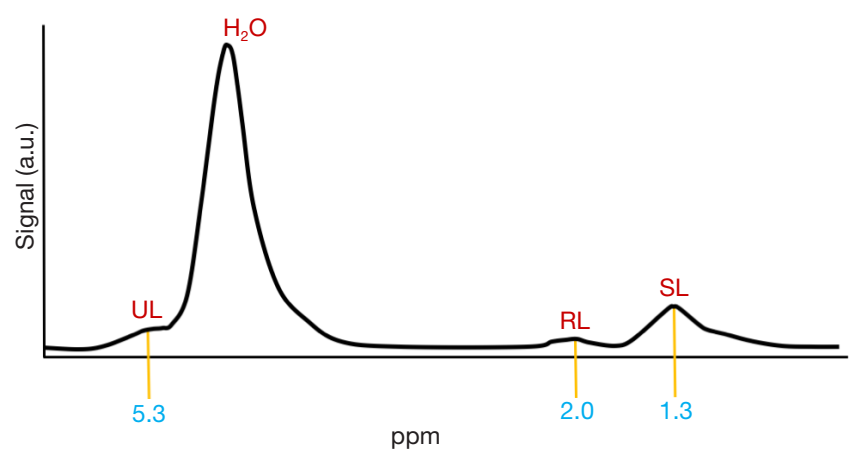

Figure 4 Proton magnetic resonance spectroscopy. Stimulated echo acquisition mode (STEAM) single-voxel 1H-MRS sequence. The spectrum that results shows peaks for water $(\mathrm{H} 2 \mathrm{O})$, saturated lipids (SL), unsaturated lipids (UL) and residual lipids (RL). Fat content is related to water content and expressed as a percentage, called bone marrow fat fraction (BMFF). This percentage is calculated using the large lipid peak at 1.3 parts per million (ppm), which are the SL, normally disregarding the smaller lipid peaks at 2.0 and $5.3 \mathrm{ppm}$, which correspond to RL and UL, but these can also be used. 1H-MRS, proton magnetic resonance spectroscopy.

measurement (57). This allows also for the calculation of $\mathrm{T} 2$, a parameter reflecting the water composition.

The trabecular bone causes susceptibility artefacts, and this will make the water and fat peaks overlap. Water and unsaturated fat peaks overlap significantly in the spine. This means that when there is a strong water peak, the extraction of the spectrum of unsaturated peak will be challenging. Diverse solutions, like increasing TE (using STEAM sequences) (58) or adding diffusion sequences (59) have been proposed to solve this problem.

Other potential disadvantage of $1 \mathrm{H}-\mathrm{MRS}$ is the existence of chemical shift displacement effects, which depend on the fat distribution around the voxel.

Besides, $1 \mathrm{H}-\mathrm{MRS}$ is not a suitable tool for retrospective analysis in studies and longitudinal studies, given every voxel needs prospective planning.

On histological correlation, it has been reported that 1H-MRS measurement of MAT demonstrates a good correlation with the amount of fat obtained in iliac crest biopsy, when this is performed in the spine (not demonstrated for the femur) (60).

Currently, there are no standard protocols to assess MAT with $1 \mathrm{H}-\mathrm{MRS}$.

\section{Water-fat imaging}

The advantage of chemical shift sequences over spectroscopy rests in the fact that the BMFF can be assessed with high spatial resolution. This is important, given the heterogeneous distribution/pattern often found in the marrow (persistence of regions of hematopoietic marrow). Fat content is calculated as a percentage (BMFF).

Some confounding factors have been found when using water-fat sequences. Multiple peaks in the fat spectrum can be found, and this can be corrected by using a precalibrated multi-peak spectrum in the signal model (53). The most frequently used is the spectrum obtained by Ren et al. on 7T tibial measurements (61). The mean spectra for bone marrow fat have also been obtained from constrained peak fitting of single voxel MRS measurements in the spine and femur $(57,62)$.

$\mathrm{T} 1$ bias effects, caused by the different $\mathrm{T} 1$ relaxation times of fat and water, can induce errors in the fat quantification. A way to solve this problem is to use long repetition times, that lengthen the acquisition times, or to use low flip angles, which is the commonly used way (63).

The presence of trabecular bone shortens the $\mathrm{T}_{2}$ ( $\left(\mathrm{T}^{*}\right.$ * decay) of the fat and water components, and this causes a quick decay of the measured gradient echo signal with TE (53). Corrections to the $\mathrm{T}^{*}$ can be performed (dual or single).

Once all these confounding factors have been addressed, it has been seen that a good agreement exists between MRS and chemical shift PDFF in the proximal femur and spine (62).

Water-fat imaging has been validated against histological samples in a cadaver study, with a good correlation obtained $(\mathrm{r}=0.77)$ (64).

A very recent study, by Schmeel et al. (65), confirms vertebral marrow PDFF obtained by chemical shift-encoding based water-fat MRI as highly accurate, repeatable and reproducible among readers, filed strengths and MRI units, highlighting its value as a quantitative imaging biomarker.

The use of chemical shift-encoding based water-fat MRI offers the invaluable advantage of providing spatially resolved assessment of bone marrow fat composition, as opposed to single-voxel $1 \mathrm{H}-\mathrm{MRS}$ acquisition, which is limited to the vertebral level of study. This feature allows to analyze anatomical variation (66). A recent study by Baum et al. using chemical shift-encoding based water-fat MRI obtained in a 3T magnet (eight-echo 3D spoiled gradientecho sequence), relative age-related PDFF changes showed an anatomical variation, with more pronounced changes in the lower lumbar vertebral levels in both sexes (67).

\section{$C T$}

Bone marrow fat quantification has also been performed with 
peripheral quantitative computed tomography (pQCT) (68), but this involves high radiation doses.

Dual energy quantitative CT (DECT) has also been used to quantify MAT, with the use of phantoms (69). It has been validated against histological samples $(\mathrm{r}=0.80)$ and has a high level of correlation with water-fat imaging $(\mathrm{r}=0.88)(64)$.

\section{Bone marrow fat and bone: pathophysiology of the interactions}

\section{Age and gender}

Allowing for great individual variations, the general trend is that MAT increases with age. It has been reported that the increase with age affects both genders similarly, with men having approximately $6-10 \%$ more vertebral MAT than women in the same age group, from 20 to 60 years of age (70) (Figure 5). After menopause, MAT content increases dramatically in women (55-65 years of age), to establish a difference with men of the same age of the $10 \%$. In men the increase after 60 is gradual (71).

\section{Exercise and unloading}

Very interesting studies have been carried out to analyze the association MAT and skeletal unloading, some of them related to space programs.

One of them was prospectively conducted on 24 women, who had 60 days of bed rest (72). MAT was measured with MRI. An increase in MAT and persistence of this increase for one year was documented.

Studies performed in the eighties exposing rodents to microgravity and unloading showed that once loading resumed bone mineral acquisition increased and MAT reverted to normal (73). More recently, the precise genetic expression and molecular pathways have been elucidated (74).

Bone response to exercise includes changes in MAT. A study demonstrated that in young female athletes performing weight-bearing impact sports, MAT (assessed in the tibia with pQCT) was lower than in athletes performing non-weight-bearing impact sports and nonathlete controls (75). They found that in all women, marrow adiposity is a predictor of bone strength, independently of loading history, size or body composition. In children, a study randomizing a small group into threetime weekly 20-minute sessions of physical and nonphysical activities showed a significant reduction of MAT (measured with MRI) in the physical activity group (76).
A study on rodents on a regular diet versus a high fat diet that could voluntarily exercise demonstrated that MAT accumulation (assessed with microscanners) triggered by a high fat diet could be suppressed by exercise, and more importantly, that exercise significantly increased bone quantity in both groups (77). This suggests that the beneficial effect of exercise over BMD may be mediated by a decrease in MAT as well as an increase in bone formation.

\section{BMD—osteoporosis}

The increase in MAT in osteoporosis was already noted by Meunier at the beginning of the 1970s, in a series of iliac bone biopsies (78).

An interesting question for researchers regarding osteoporosis, is whether MAT accumulation is earlier, simultaneous with or later in time than the loss of BMD. Aging has been proven to be associated with an increase in MAT, simultaneous to a decrease in trabecular bone density (79) (Figure 6). In animal studies, some other conclusions have been reached. In mice, trabecular bone starts to be lost as early as 8 weeks of life, with the increase in MAT only being apparent in later stages (80). In a study performed in rabbits, in which osteoporosis was induced with glucocorticoids, it was seen that the increase in MAT preceded the loss of BMD (81).

Several recent studies conducted by Shen et al. in different ethnical populations report a significant negative association between MAT (measured with 1H-MRS) and BMD for healthy men and women $(48,82,83)$. In their largest study, they observed this inverse relationship in anatomically matched regions, non-matched regions and regional and whole-body assessment.

The same conclusion was reached in a different ethnical cohort (Chinese). Measurement of MAT was obtained with MRS, and measurement of BMD obtained by DXA. Higher MAT content was found in age-matched subjects with osteoporotic-range BMD in comparison with osteopenic or normal BMD range subjects (84). Also in Chinese population, studies performed with MRS and DXA in age and body mass index (BMI) matched postmenopausal women demonstrated that MAT content was higher in patients with osteoporosis than osteopenia or normal BMD $(55,85)$.

As the amount of MAT increases, there are also histological changes within the tissue $(18,86)$. As previously described, fat and bone are capable of mutual regulation.

In histological evaluation, the composition of MAT in postmenopausal women also demonstrates a 

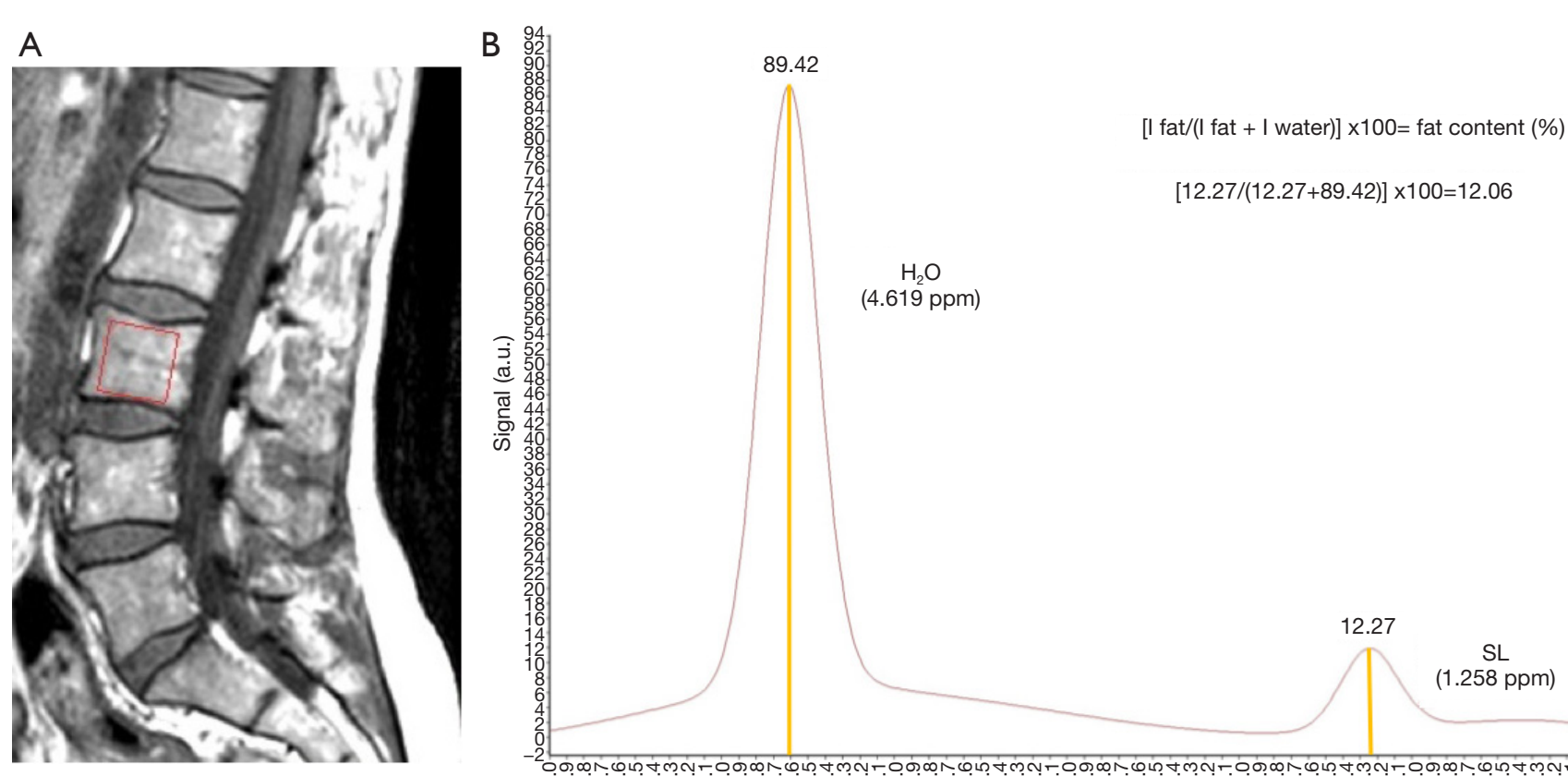

C

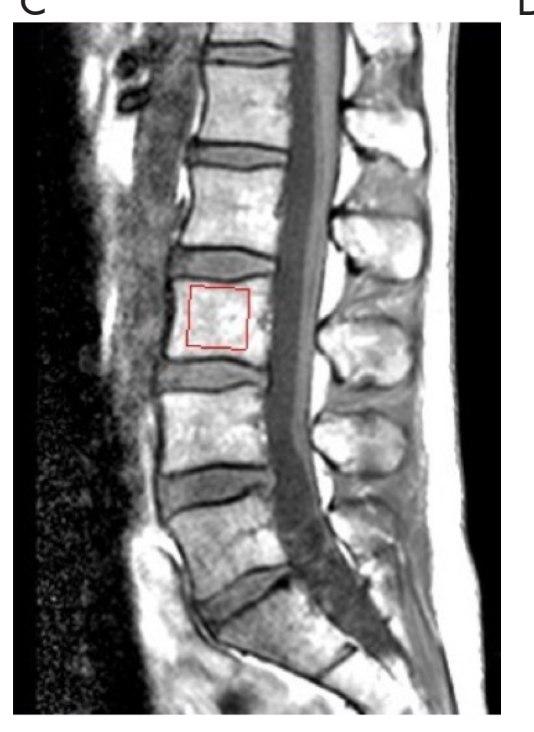

D

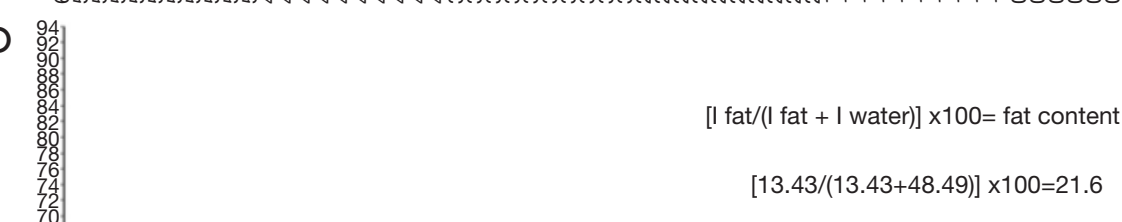

$\mathrm{H}_{2} \mathrm{O}$

(4.619 ppm)

$\mathrm{SL}$

(1.258 ppm)

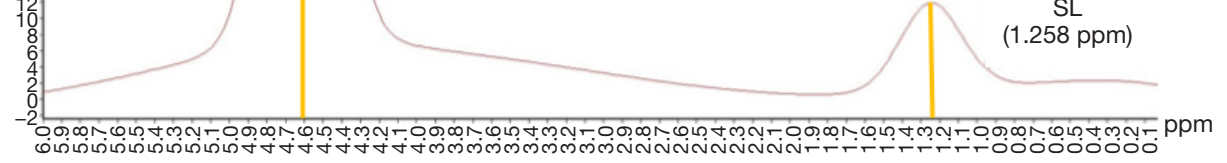

$[13.43 /(13.43+48.49)] \times 100=21.6$

Figure 5 Comparative spectra between a 43-year-old woman [A, T1 sagittal planning image with vertebral body voxel (red box); B, spectral curve] and a 42-year-old man [C, T1 sagittal planning image with vertebral body voxel (red box); D, spectral curve]. A very subtle difference in the height (signal) of the lipid peak (at $1.3 \mathrm{ppm}$ ) can be appreciated, when comparing woman (12.27) and man (13.43), with a slightly higher peak present in the spectrum for the man, and less total water (89.42 in woman, 48.49 in man). Fat fraction \{calculated as fat content $(\%)=[\mathrm{I}$ fat $/(\mathrm{I}$ fat $+\mathrm{I}$ water $)] \times 100$, where I is signal amplitude $]$ in the woman was calculated at $12.06 \%$, and $21.6 \%$ in the man. Men have approximately $6-10 \%$ more vertebral MAT than women in the 20 to 60 age group. SL, saturated lipids; MAT, marrow adipose tissue. 
profile of decreased saturated fatty acids and increased monounsaturated fatty acids, particularly in women that have had a fracture (87).

Besides, in studies based on therapeutic interventions, it has been histologically proven that 1 year of estrogen therapy decreases bone marrow adipocyte volume and prevents an increase in number (88). Histological studies on the use of risedronate for 3 years (89) and teriparatide for 1 year (90) have demonstrated the same effect. The effect of zoledronic acid has been evaluated only with MRS, but this has been seen to trigger a dramatic decrease in MAT besides from decreasing the risk of fracture $(81,91)$.

Other studies have focused on the evaluation of the association of MAT and volumetric BMD (vBMD) and the different mineralized components of bone (trabecular and cortical), obtained through quantitative CT (QCT) or pQCT.

Di Iorgi et al. have published two studies using QCT to analyze the bone component in healthy populations. The first one focused on the relationship between cancellous bone in the axial skeleton (vBMD) and femoral cortical bone [using cortical bone area (CBA) as a parameter for appendicular skeleton] and MAT density in femurs of healthy teenagers and young adults, and found an inverse relation between bone marrow adiposity and the amount of bone in axial and appendicular skeleton, even after adjusting for weight, height,
A

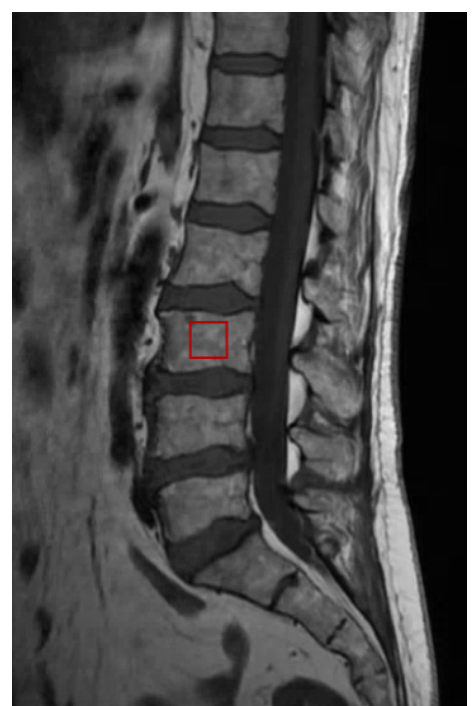

B

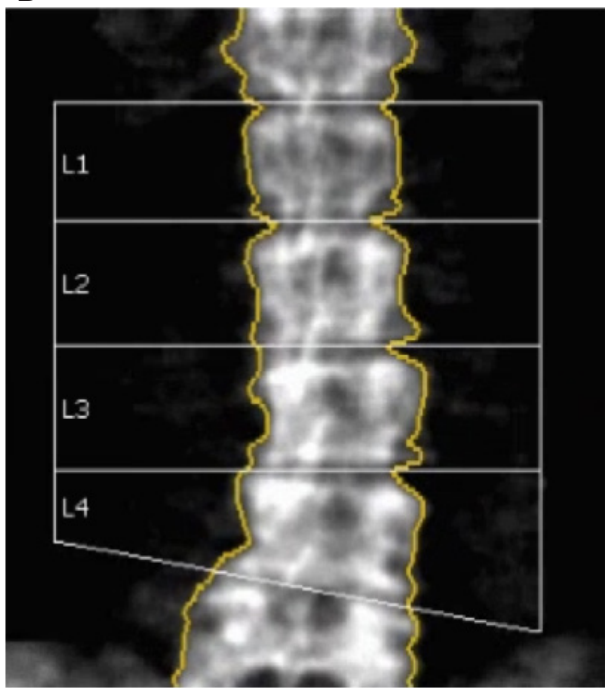

C

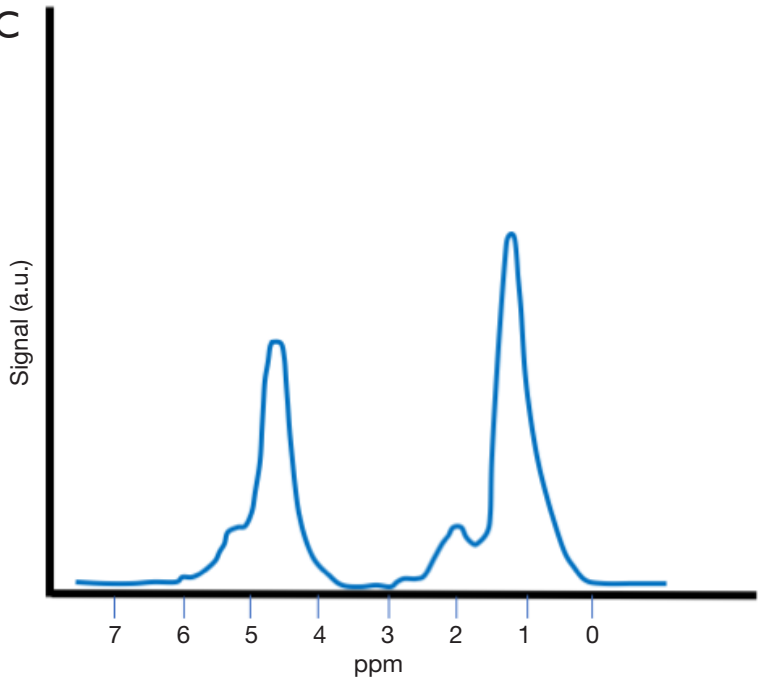

Ref. de la densitometría: L1-L4 (DMO)

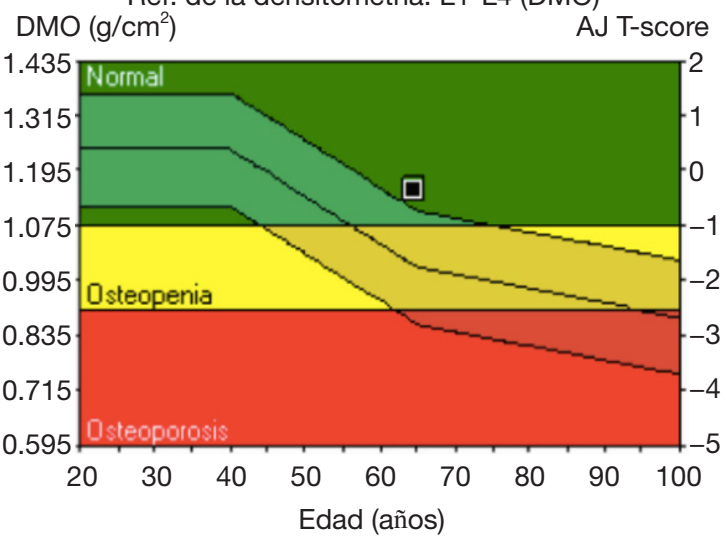


$\mathrm{D}$

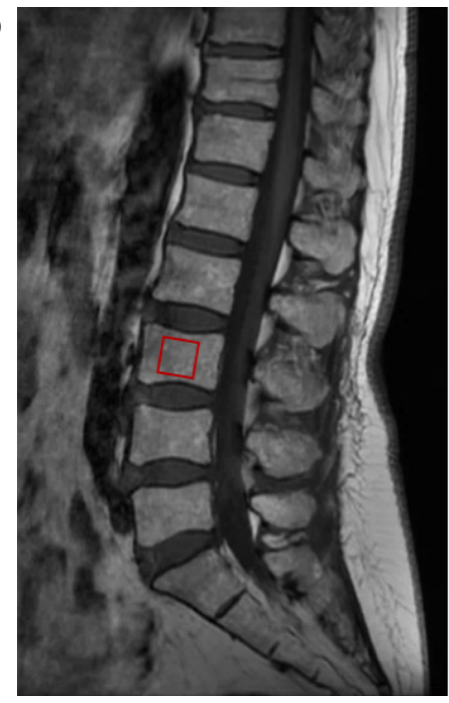

E

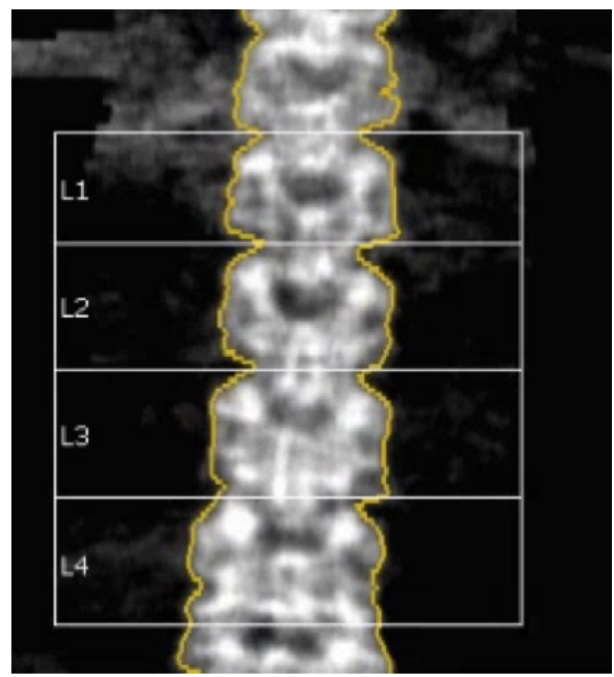

$\mathrm{F}$

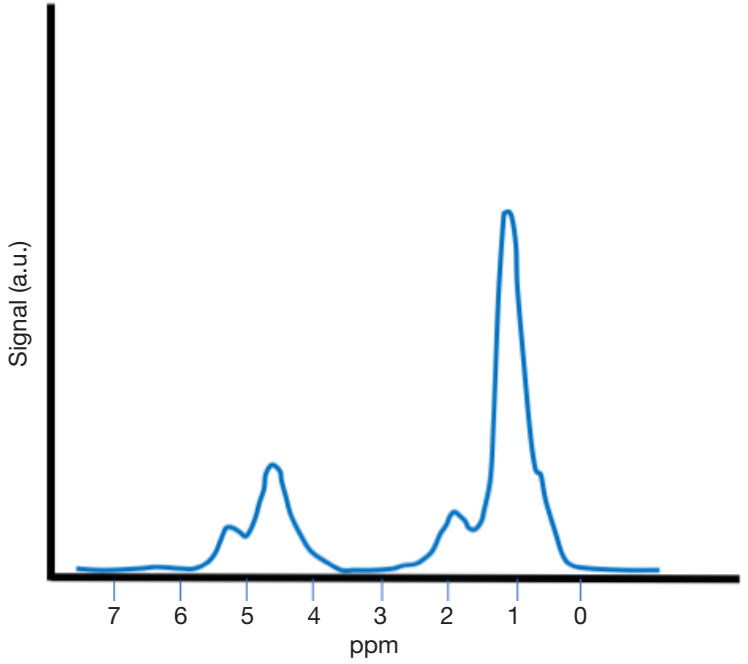

Ref. de la densitometría: L1-L4 (DMO)

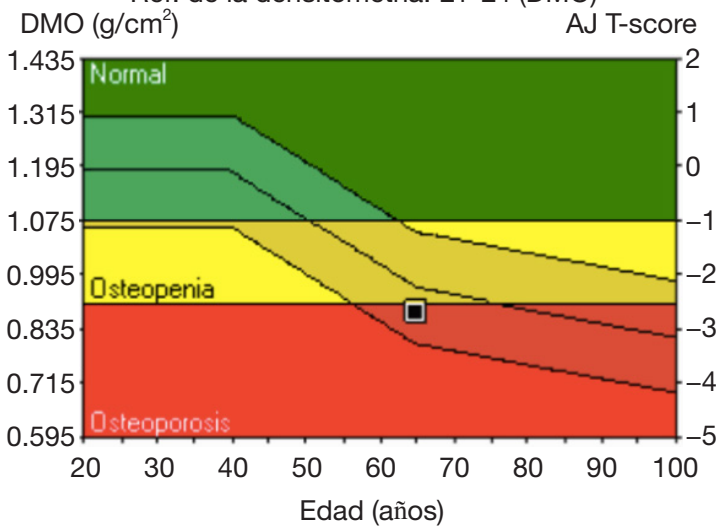

Figure 6 Comparison of spectral readings in two subjects, with normal BMD and in the osteoporosis range. (A) T1 sagittal planning image with vertebral body voxel (red box) in a 65-year-old woman; (B) BMD obtained with DXA is in the normal range (T=-0.3); (C) representation of the obtained spectral curve, with an increase in the lipid peak, and a decrease in the water peak, when compared to young subjects; (D) T1 sagittal planning image with vertebral body voxel (red box) in another 65-year-old woman affected by osteoporosis; (E) BMD obtained by DXA is in the osteoporotic range ( $\mathrm{T}=-2.6)$; $(\mathrm{F})$ spectral reading shows a high peak of lipids, with substantial decrease of water contents. BMD, bone mineral density; DXA, dual-energy X-ray absorptiometry.

DXA fat mass and size of the bone (92). A more recent longitudinal study focused on healthy young females and compared CBA with MAT in the femur, finding that CBA is inversely related to changes in the MAT density (93).

In a study based on the Iceland AGES Reykjavik cohort, Schwartz et al. (79) found that in older women, higher MAT content (measured by MRS) was associated with lower trabecular bone (vBMD) in the spine, total hip and femoral neck, but not with lower cortical bone. In old men, there were no statistically significant associations between MAT and $\mathrm{VBMD}$ (trabecular or cortical), in the aforementioned locations.

Bredella et al. had already previously found that MAT correlated inversely with vBMD measured in the spine, in 
a smaller group of premenopausal women with different BMIs, with a correlation that remained significant after adjusting for VAT (22).

pQCT studies are more scarce. A recent study found no correlation between MAT (using MRS) and trabecular and cortical vBMD (distal radius and tibia) in a sample of nondiabetic man from the MrOS study (94).

High resolution pQCT (HR-pQCT) was also used in one study that evaluated bone microarchitecture in the distal radius in middle aged obese men. MAT measured in the vertebrae (using MRS) correlated inversely with cortical vBMD, cortical area and trabecular thickness, and this remained significant even after controlling for BMD assessed by DXA in the lumbar spine (95). More recently, has also been applied to the study of correlation of MAT and fractures (96).

Finally, some studies have focused on the use of MRI (97), demonstrating that femoral CBA (measured with MRI) is inversely associated with MAT in the middle third of femurs in young as well as in old subjects.

\section{Fractures}

The relation between MAT and occurrence of fracture is complex.

The latest evidence appears to point towards the intrinsic composition of MAT as a factor to influence risk of fracture. Using MRS, Yeung et al. (84) studied a group of postmenopausal women and found that fat UI was significantly lower in osteoporotic and osteopenic women, compared to individuals with normal BMD and a control group of premenopausal women. They also found an inverse correlation between fat content and UI. A subsequent study confirmed these results, using bone marrow aspirates and comparing these results with a different type of MR spectroscopy assessment tool (98).

A more recent study focused on the association between vertebral MAT (measured with MRS) and insufficiency fractures, comparing two groups of postmenopausal women: diabetic and non-diabetic. They could not find an association between vertebral MAT and insufficiency fractures, but they found an association between low unsaturation levels and insufficiency fractures, independent of age, ethnicity and spinal vBMD (measured with QCT) (54).

An association between prevalent vertebral fractures and higher MAT and histological analysis has been reported in at least two different studies $(60,86)$. Cohen et al. demonstrated that the number, size and volume of adipocytes in postmenopausal women with idiopathic osteoporosis (low trauma fractures or low BMD) were found to be greater than those of controls (adjusted for age and BMI) (60).

A study by Schwartz et al. (79), with a 257 old-adult population sample, found that people with prevalent vertebral fractures had higher mean MAT (adjusted for age and gender), but they did not find an association between MAT and history of fractures (all types) or insufficiency fractures in men or women.

Finally, some studies introduce the concept that increased MAT (measured with MRS) can contribute to "bone weakness", independently of BMD (measured by DXA) and introduce a MAT/BMD ratio as an indicator of bone weakening. The features of bone weakness they consider are Schmorl's nodes, endplate fractures, body wedging and compression fractures $(99,100)$.

A very recent study, using HR-pQCT (96) in 77 women (ages 40 to 70) with a recent non-vertebral fracture and 226 healthy controls demonstrated a direct association between MAT and cortical porosity and an indirect association with the number, quality and separation of trabeculae. They concluded that the discrimination of women with non-vertebral fracture from controls improved significantly when MAT and cortical porosity were added.

The conclusion that can be drawn is that vertebral fractures may be associated with higher MAT content, independently of BMD.

\section{Obesity}

The relationship between MAT and other fat deposits in the body is insufficiently characterized (101). Studies are scarce.

The relationship between MAT, total body fat, visceral and subcutaneous tissue fat is not consistent, and studies come to different conclusions. Some studies have found a positive association between visceral fat and MAT (in obese premenopausal women) (22), but some studies have reported no association $(102,103)$.

Ermetici et al. recently explored the relationship between obesity and intrinsic MAT composition in premenopausal women (104). MAT content and UI were seen to be similar in obese and non-obese premenopausal women.

A recent study by Tencerova et al. (105) on mice has shown that a high fat diet decreased trabecular bone mass by $29 \%$, cortical thickness by $5 \%$ and increased MAT content by $184 \%$, and also that the MAT increase did 
not demonstrate insulin resistance a pro-inflammatory phenotype, which means that it absorbs extra energy (in the form of triglycerides, affecting whole-body homeostasis). They demonstrated that the progenitor cells in the context of high fat diet were prone to adipocyte differentiation, thus decreasing osteoblastic differentiation, and therefore bone formation, with a detrimental effect on the skeleton.

Huovinen et al. (106) studied the association between early obesity and bone marrow acid composition. Their study tested the relationship between the UI, exercise history and glycemic state (amongst other clinical parameters), in two groups of young adults (normal weight and overweight) with known weight status in early childhood. The UI was not affected by obesity at the time of the study or before age 7 , but increased with age in both groups. UI was not associated with gender, physical activity or body fat composition, however, they found a faint association between fasting glucose and UI.

The effect of weight loss has also been studied, although literature is still scarce.

Most studies have focused on bariatric surgery. Two studies by Schafer et al. (107) and Kim et al. (103) investigated the effects of Roux-en-Y gastric bypass (RYGB) on vertebral MAT (measured with MRS), in two groups of morbidly obese diabetic and non-diabetic women. In non-diabetic patients, MAT remained stable 6 months after surgery, despite the decline of fat in overall fat mass. In diabetic patients, RYGB surgery triggered a significant reduction in MAT. Greater declines in HbA1C and increases in IGF-1 (in both groups of patients, diabetic and non-diabetic) were associated with a decline in MAT. MAT changes and BMD changes (in spine and femoral neck) were negatively associated, independently of age and menopause.

Interestingly though, the effects of bariatric surgery in the skeleton are variable and not well understood. In an almost synchronic study to Kim et al.'s, Bredella et al. (108) compared RYGB and gastric sleeve gastrectomy, and no change in MAT content was reported after RYGB surgery, but they found an association between sleeve gastrectomy and increase in MAT.

In a different study from the same year, by Yu et al., RYGB was associated with a $43 \%$ increase in the risk of non-vertebral fracture, when compared with adjustable gastric banding (109).

\section{Anorexia nervosa $(A N)$}

$\mathrm{AN}$ is a serious condition, with multiple repercussions, some of them skeletal.

Although there is a dramatic depletion of body fat [VAT and subcutaneous adipose tissue (SAT)] (110), it was demonstrated that MAT (measured with MRS) is increased (111). A study demonstrated that compared with normal weight age-matched controls, women with AN had higher content of MAT in lumbar vertebrae and femur. After adjusting for BMI, MAT was seen to correlate inversely with BMD (measured with DXA) (111). In a different study, composition of the MAT was assessed with MRS, finding no significant difference between the two groups (112).

The Pref-1, a transmembrane protein that is inhibitory of adipocyte and osteoblast differentiation, that appears raised in situations of estrogen deficiency (amenorrhea associated to AN) has been seen to be positively associated with MAT in $\mathrm{AN}$ and decrease with recovery form the disorder (113).

The rationale behind this phenomenon of decreased VAT and SAT and increased MAT is still unclear, postulated as a mechanism of protection for skeletal health.

\section{Diabetes}

Several studies have investigated the relationship between MAT and diabetes.

Abnormalities in cortical architecture and an increase in MAT have demonstrated in type I diabetes $(114,115)$. In type II diabetes, there is no increase in MAT, and insufficiency fracture risk is increased, independently of BMD (116). A study by Patsch et al. (54), focused on the association between vertebral MAT (measured with MRS) and insufficiency fractures, compared two groups composed of diabetic and non-diabetic postmenopausal women. MAT in the diabetic group had a composition that showed relatively more saturated lipids (lower unsaturation) than in the non-diabetic group. They could not find an association between vertebral MAT and insufficiency fractures in any of the groups, but they found an association between low unsaturation levels and insufficiency fractures, independent of age, ethnicity and spinal $\mathrm{vBMD}$ (measured with QCT). This makes things slightly confusing in regard to fracture risk, however other factors, such as cortical porosity or microvascular impairment are also involved (117).

These results coincided with the results of a previous study by Baum et al. that compared a group of diabetic postmenopausal women with age and BMI matched controls. Vertebral MAT was similar in both groups, but the levels of unsaturation were lower in the diabetic group (52). In the same study, it was observed that in 
diabetic women higher HbA1c levels were associated with higher vertebral MAT content. A recent study by Yu et al. (102) confirmed the same finding in the lumbar spine and femoral metaphysis. Machann et al. (118) in a recent study, assessed the UI in six different adipose tissue compartments, amongst them MAT in the tibia, and investigated the associations with intrahepatic lipids, insulin sensitivity and adipose tissue volumes. They found UI to be location dependent. Interestingly, they found the level of unsaturation in tibial MAT negatively correlated with insulin-sensitivity. This discrepancy with the results obtained by Baum et al. in vertebral MAT (52) could be explained, at least partly, by the fact that $1 \mathrm{H}-\mathrm{MRS}$ studies on MAT composition are unreliable when there is a high water fraction (119), as recently proven by Lundbom $e t a l$.

Kim et al. (103), in their study on bariatric surgery patients, did not find that MAT was higher in diabetic than in non-diabetic as a baseline, but demonstrated that RYGB surgery triggered a significant reduction in MAT in the diabetic group, and also that greater declines in $\mathrm{HbAlC}$ and increases in IGF-1 in both groups of patients undergoing RYGB (diabetic and non-diabetic) were associated with a decline in MAT.

Recently, Ermetici et al. (104) found a negative correlation between MAT and insulin sensitivity [estimated using the homeostasis model assessment of insulin resistance (HOMA-IR)] in premenopausal women. Even more recently Zhu et al. (120) reported that elevated HOMA-IR was linked to higher MAT (measured as PDFF with MRS) in postmenopausal women with newly diagnosed type II diabetes, independently of body composition (measured with DXA).

Overall, these findings confirm a strong relationship between glucose metabolism, glycemic control and MAT.

A very recent study comparing children with type I diabetes and matched controls to determine the parameters linked to bone health and risk of fracture showed no difference in vertebral marrow adiposity (121). In the previously mentioned study by Huovinen et al. (106) (aimed at testing UI in MAT against different clinical parameters amongst them indicators of glycemic status in two groups of young adults with normalweight and overweight) neither fasting insulin nor insulin resistance (measured using the aforementioned HOMA-IR model) were seen to correlate with UI in MAT.

Studies in men have demonstrated slightly different results: as part of the MrOS study (156 men aged 74-96), Sheu et al. (94) found that MAT was higher in diabetic men, however, the result did not remain significant when two men treated with thiazolidinediones were excluded.

Oral antidiabetic drugs, such as thiazolidinediones, act as insulin-sensitizers. In mice, rosiglitazone has been proven to stimulate adipogenesis and decrease osteoblastogenesis (and BMD) (122). A large clinical trial on the use of rosiglitazone demonstrated an increase in marrow adiposity and fracture risk (123).

\section{Other clinical scenarios}

There are other clinical scenarios which have been even less extensively studied, in the MAT and bone interaction.

Radiation and chemotherapy have a tremendous impact on the bone marrow. In some cases, the radiation will be locally administered and the bone marrow will suffer collateral damage (e.g., prostate cancer) but in some cases the irradiation will be ablative (total body, prior to bone marrow transplant). Repopulation usually occurs with increased adipocyte content $(124,125)$. The risk of fracture in irradiated regions is three times as high (126). Recent insights on MAT and fracture relationship suggest this is linked to the increase in MAT.

Also, bone loss and increased facture risk is increased in alcoholism. A study in rodent models shows that alcohol intake is associated with a significant increase in MAT (127).

\section{Future and implications}

The potential diagnostic and therapeutic implications that can be extracted from the research of MAT are incredibly relevant.

Osteoporosis and osteopenia are highly prevalent, and may have devastating consequences in morbidity and mortality through the event of insufficiency fractures. This is especially evident in situations in which these conditions present early in life, which is in the context of cancer treatment, for example in the context of total irradiation for bone marrow transplants.

In the case of radiotherapy patients, the quantification of fat fraction allows an insight on the hematological toxicity of treatments, acting as a clinical measure of bone marrow dosimetry (128). Recent studies orientated towards the measurement of bone marrow cellularity for radiation dosimetry purposes have used two-point Dixon (128) and single and multiple peak iterative decomposition of water and fat with echo asymmetry and least-squares estimation [singlepeak iterative decomposition of water and fat with echo asymmetry and least-squares (SP-IDEAL) and multipeak 
(MP)-IDEAL respectively] (129), to obtain the fat fraction. In the study by Pichardo et al. (129), the SP-IDEAL sequence was seen to correlate with the adipocyte volume fraction obtained from histology, which is the appropriate parameter to account for patient-specific cellularity in bone marrow mass in predictive equations, consistent with the existing models of skeletal dosimetry on micro-CT.

The development of agents that could act blocking adipogenesis and diverting differentiation of the bone marrow precursors into osteoblastic linage, for example, could favor long term treatment of these conditions.

In diabetic patients, especially in those in which type I diabetes onset happens early in life, and the risk of fracture becomes already high in their youth, similar benefits could be obtained from acting over adipogenesis and favoring bone forming pathways.

In type II diabetics, the knowledge on the type on MAT composition could help on tailoring the types of interventions (through diet and also medication) and eventually monitoring control or predicting possible longterm effects of the disease.

\section{Conclusions}

The MAT-bone interaction is a fertile area of research.

MAT has a role in bone health, through its paracrine and endocrine interaction with the other components of bone. Many metabolic disorders (osteoporosis, obesity, diabetes) have a complex and still not well understood relationship with bone health, and just as they relate to the mineralized component of bone, there is mounting evidence establishing solid links with MAT and MAT composition.

The development of imaging, and more specially MRbased techniques, has unlocked numerous pathways to assess and quantify MAT, and thus set the ground to carry out studies to further elucidate the implications of MAT in physiologic and pathologic conditions.

This offers a tremendous opportunity in the clinical field, to potentially develop preventative strategies and treatments for very prevalent chronic conditions.

This work has reviewed the existing evidence relating MAT to metabolic disorders with an impact on bone health, highlighting the role that imaging methods play in helping with quantification and diagnosis.

\section{Acknowledgments}

Funding: None.

\section{Footnote}

Provenance and Peer Review: With the arrangement by the Guest Editors and the editorial office, this article has been reviewed by external peers.

Conflicts of Interest: All authors have completed the ICMJE uniform disclosure form (available at http://dx.doi. org/10.21037/qims.2020.01.11). The special issue "Body Composition Imaging" was commissioned by the editorial office without any funding or sponsorship. GG served as the unpaid Guest Editor of the special issue and serves as an unpaid editorial board member of Quantitative Imaging in Medicine and Surgery. AB served as the unpaid Guest Editor of the special issue. The authors have no other conflicts of interest to declare.

Open Access Statement: This is an Open Access article distributed in accordance with the Creative Commons Attribution-NonCommercial-NoDerivs 4.0 International License (CC BY-NC-ND 4.0), which permits the noncommercial replication and distribution of the article with the strict proviso that no changes or edits are made and the original work is properly cited (including links to both the formal publication through the relevant DOI and the license). See: https://creativecommons.org/licenses/by-nc-nd/4.0/.

\section{References}

1. Guerri S, Mercatelli D, Aparisi Gómez MP, Napoli A, Battista G, Guglielmi G, Bazzocchi A. Quantitative imaging techniques for the assessment of osteoporosis and sarcopenia. Quant Imaging Med Surg 2018;8:60-85.

2. Curtis E, Litwic A, Cooper C, Dennison E. Determinants of Muscle and Bone Aging. J Cell Physiol 2015;230:2618-25.

3. Tagliaferri C, Wittrant Y, Davicco MJ, Walrand S, Coxam $\mathrm{V}$. Muscle and bone, two interconnected tissues. Ageing Res Rev 2015;21:55-70.

4. Bonewald L. Use it or lose it to age: A review of bone and muscle communication. Bone 2019;120:212-8.

5. Ponti F, Guerri S, Sassi C, Battista G, Guglielmi G, Bazzocchi A. Imaging of diabetic bone. Endocrine 2017;58:426-41.

6. Bazzocchi A, Guglielmi G. Vertebral Fracture Identification. Semin Musculoskelet Radiol 2016;20:317-29.

7. Hardouin P, Rharass T, Lucas S. Bone Marrow Adipose Tissue: To Be or Not To Be a Typical Adipose Tissue? 
Front Endocrinol (Lausanne) 2016;7:85.

8. Ghali O, Al Rassy N, Hardouin P, Chauveau C. Increased Bone Marrow Adiposity in a Context of Energy Deficit: The Tip of the Iceberg? Front Endocrinol (Lausanne) 2016;7:125.

9. Lecka-Czernik B, Stechschulte LA, Czernik PJ, Sherman SB, Huang S, Krings A. Marrow Adipose Tissue: Skeletal Location, Sexual Dimorphism, and Response to Sex Steroid Deficiency. Front Endocrinol (Lausanne) 2017;8:188.

10. Cornish J, Wang T, Lin JM. Role of Marrow Adipocytes in Regulation of Energy Metabolism and Bone Homeostasis. Curr Osteoporos Rep 2018;16:116-22.

11. Hardouin P, Pansini V, Cortet B. Bone marrow fat. Joint Bone Spine 2014;81:313-9.

12. Beresford JN, Bennett JH, Devlin C, Leboy PS, Owen ME. Evidence for an inverse relationship between the differentiation of adipocytic and osteogenic cells in rat marrow stromal cell cultures. J Cell Sci 1992;102:341-51.

13. Horowitz MC, Berry R, Holtrup B, Sebo Z, Nelson T, Fretz JA, Lindskog D, Kaplan JL, Ables G, Rodeheffer MS, Rosen CJ. Bone marrow adipocytes. Adipocyte 2017;6:193-204.

14. Scheller EL, Doucette CR, Learman BS, Cawthorn WP, Khandaker S, Schell B, Wu B, Ding SY, Bredella MA, Fazeli PK, Khoury B, Jepsen KJ, Pilch PF, Klibanski A, Rosen CJ, MacDougald OA. Region-specific variation in the properties of skeletal adipocytes reveals regulated and constitutive marrow adipose tissues. Nat Commun. 2015 Aug 6;6:7808.

15. Lecka-Czernik B, Stechschulte LA. Bone and fat: A relationship of different shades. Arch Biochem Biophys 2014;561:124-9.

16. Rharass T, Lucas S. Mechanisms in endocrinology: Bone marrow adiposity and bone, a bad romance? Eur J Endocrinol 2018;179:R165-82.

17. Cawthorn WP, Scheller EL, Learman BS, Parlee SD, Simon BR, Mori H, Ning X, Bree AJ, Schell B, Broome DT, Soliman SS, DelProposto JL, Lumeng CN, Mitra A, Pandit SV, Gallagher KA, Miller JD, Krishnan V, Hui SK, Bredella MA, Fazeli PK, Klibanski A, Horowitz MC, Rosen CJ, MacDougald OA. Bone marrow adipose tissue is an endocrine organ that contributes to increased circulating adiponectin during caloric restriction. Cell Metab 2014;20:368-75.

18. Verma S, Rajaratnam JH, Denton J, Hoyland JA, Byers RJ. Adipocytic proportion of bone marrow is inversely related to bone formation in osteoporosis. J Clin Pathol
2002;55:693-8.

19. Singh L, Tyagi S, Myers D, Duque G. Good, Bad, or Ugly: the Biological Roles of Bone Marrow Fat. Curr Osteoporos Rep 2018;16:130-7.

20. Wan Y, Chong LW, Evans RM. PPAR- regulates osteoclastogenesis in mice. Nat Med 2007;13:1496-503.

21. Lecka-Czernik B. Marrow fat metabolism is linked to the systemic energy metabolism. Bone 2012;50:534-9.

22. Bredella MA, Torriani M, Ghomi RH, Thomas BJ, Brick DJ, Gerweck AV, Rosen CJ, Klibanski A, Miller KK. Vertebral bone marrow fat is positively associated with visceral fat and inversely associated with IGF-1 in obese women. Obesity (Silver Spring) 2011;19:49-53.

23. Fan Y, Hanai JI, Le PT, Bi R, Maridas D, DeMambro V, Figueroa CA, Kir S, Zhou X, Mannstadt M, Baron R, Bronson RT, Horowitz MC, Wu JY, Bilezikian JP, Dempster DW, Rosen CJ, Lanske B. Parathyroid Hormone Directs Bone Marrow Mesenchymal Cell Fate. Cell Metab 2017;25:661-72.

24. Fairfield H, Falank C, Harris E, Demambro V, McDonald M, Pettitt JA, Mohanty ST, Croucher P, Kramer I, Kneissel M, Rosen CJ, Reagan MR. The skeletal cell-derived molecule sclerostin drives bone marrow adipogenesis. J Cell Physiol 2018;233:1156-67.

25. Lewiecki EM. Role of sclerostin in bone and cartilage and its potential as a therapeutic target in bone diseases. Ther Adv Musculoskelet Dis 2014;6:48-57.

26. Cosman F, Crittenden DB, Adachi JD, Binkley N, Czerwinski E, Ferrari S, Hofbauer LC, Lau E, Lewiecki EM, Miyauchi A, Zerbini CA, Milmont CE, Chen L, Maddox J, Meisner PD, Libanati C, Grauer A. Romosozumab Treatment in Postmenopausal Women with Osteoporosis. N Engl J Med 2016;375:1532-43.

27. Ambrosi TH, Schulz TJ. The emerging role of bone marrow adipose tissue in bone health and dysfunction. J Mol Med 2017;95:1291-301.

28. Kajimura D, Lee HW, Riley KJ, Arteaga-Solis E, Ferron M, Zhou B, Clarke CJ, Hannun YA, DePinho RA, Guo XE, Mann JJ, Karsenty G. Adiponectin regulates bone mass via opposite central and peripheral mechanisms through FoxO1. Cell Metab 2013;17:901-15.

29. Zhang P, Peterson M, Su GL, Wang SC. Visceral adiposity is negatively associated with bone density and muscle attenuation. Am J Clin Nutr 2015;101:337-43.

30. Karsenty G, Ferron M. The contribution of bone to whole-organism physiology. Nature 2012;481:314-20.

31. Wei J, Ferron M, Clarke CJ, Hannun YA, Jiang H, Blaner WS, Karsenty G. Bone-specific insulin resistance disrupts 
whole-body glucose homeostasis via decreased osteocalcin activation. J Clin Invest 2014;124:1-13.

32. Naveiras O, Nardi V, Wenzel PL, Hauschka PV, Fahey F, Daley GQ. Bone-marrow adipocytes as negative regulators of the haematopoietic microenvironment. Nature 2009;460:259-63.

33. Adler BJ, Green DE, Pagnotti GM, Chan ME, Rubin CT. High fat diet rapidly suppresses B lymphopoiesis by disrupting the supportive capacity of the bone marrow niche. PLoS One 2014;9:e90639.

34. Li Y, Toraldo G, Li A, Yang X, Zhang H, Qian WP, Weitzmann MN. B cells and T cells are critical for the preservation of bone homeostasis and attainment of peak bone mass in vivo. Blood 2007;109:3839-48.

35. Bonomo A, Monteiro AC, Gonçalves-Silva T, CordeiroSpinetti E, Galvani RG, Balduino A. A T Cell View of the Bone Marrow. Front Immunol 2016;7:184.

36. Keaveny TM, Morgan EF, Niebur GL, Yeh OC. Biomechanics of trabecular bone. Annu Rev Biomed Eng. 2001;3:307-33.

37. Hodge WA, Fijan RS, Carlson KL, Burgess RG, Harris WH, Mann RW. Contact pressures in the human hip joint measured in vivo. Proc Natl Acad Sci USA 1986;83:2879-83.

38. Halgrin J, Chaari F, Markiewicz É. On the effect of marrow in the mechanical behavior and crush response of trabecular bone. J Mech Behav Biomed Mater 2012;5:231-7.

39. Pansini V, Monnet A, Salleron J, Hardouin P, Cortet B, Cotten A. 3 Tesla (1) H MR spectroscopy of hip bone marrow in a healthy population, assessment of normal fat content values and influence of age and sex. J Magn Reson Imaging 2014;39:369-76.

40. Gurkan UA, Akkus O. The Mechanical Environment of Bone Marrow: A Review. Ann Biomed Eng 2008;36:1978-91.

41. Tøndevold E, Eriksen J, Jansen E. Observations on long bone medullary pressure in relation to mean arterial blood pressure in the anaesthetized dog. Acta Orthop Scand 1979;50:527-31.

42. Davis LB, Praveen SS. Nonlinear versus linear behavior of calcaneal bone marrow at different shear rates. In: American Society of Biomechanics Annual Meeting, Blacksburg, VA, 2006. Available online: http:// www. asbweb.org/conferences/2006/pdfs/304.pdf

43. Simkin PA. Marrow fat may distribute the energy of impact loading throughout subchondral bone. Rheumatology (Oxford) 2018;57:414-8.

44. Carter DR, Hayes WC. The compressive behavior of bone as a two-phase porous structure. J Bone Joint Surg Am 1977;59:954-62.

45. Seeman E. Age- and menopause-related bone loss compromise cortical and trabecular microstructure. J Gerontol A Biol Sci Med Sci 2013;68:1218-25.

46. Braidotti P, Stagni L. A critical damping approach for assessing the role of marrow fat on the mechanical strength of trabecular bone. Med Hypotheses 2007;69:43-6.

47. Aparisi Gómez MP. Nonspinal Fragility Fractures. Semin Musculoskelet Radiol 2016;20:330-44.

48. Shen W, Scherzer R, Gantz M, Chen J, Punyanitya M, Lewis CE, Grunfeld C. Relationship between MRImeasured bone marrow adipose tissue and hip and spine bone mineral density in African-American and Caucasian participants: the CARDIA study. J Clin Endocrinol Metab 2012;97:1337-46.

49. Shen W, Gong X, Weiss J, Jin Y. Comparison among T1-Weighted Magnetic Resonance Imaging, Modified Dixon Method, and Magnetic Resonance Spectroscopy in Measuring Bone Marrow Fat. J Obes 2013;2013:298675.

50. Bandirali M, Di Leo G, Papini GD, Messina C, Sconfienza LM, Ulivieri FM, Sardanelli F. A new diagnostic score to detect osteoporosis in patients undergoing lumbar spine MRI. Eur Radiol 2015;25:2951-9.

51. Griffith JF, Yeung DKW, Leung JCS, Kwok TCY, Leung PC. Prediction of bone loss in elderly female subjects by MR perfusion imaging and spectroscopy. Eur Radiol 2011;21:1160-9.

52. Baum T, Yap SP, Karampinos DC, Nardo L, Kuo D, Burghardt AJ, Masharani UB, Schwartz AV, Li X, Link TM. Does vertebral bone marrow fat content correlate with abdominal adipose tissue, lumbar spine bone mineral density, and blood biomarkers in women with type 2 diabetes mellitus? J Magn Reson Imaging 2012;35:117-24.

53. Karampinos DC, Ruschke S, Dieckmeyer M, Diefenbach M, Franz D, Gersing AS, Krug R, Baum T. Quantitative MRI and spectroscopy of bone marrow. J Magn Reson Imaging 2018;47:332-53.

54. Patsch JM, Li X, Baum T, Yap SP, Karampinos DC, Schwartz AV, Link TM. Bone marrow fat composition as a novel imaging biomarker in postmenopausal women with prevalent fragility fractures. J Bone Miner Res 2013;28:1721-8.

55. Li X, Kuo D, Schafer AL, Porzig A, Link TM, Black D, Schwartz AV. Quantification of vertebral bone marrow fat content using 3 Tesla MR spectroscopy: reproducibility, vertebral variation, and applications in osteoporosis. J Magn Reson Imaging 2011;33:974-9. 
56. Singhal V, Miller KK, Torriani M, Bredella MA. Shortand long-term reproducibility of marrow adipose tissue quantification by $1 \mathrm{H}-\mathrm{MR}$ spectroscopy. Skeletal Radiol 2016;45:221-5.

57. Dieckmeyer M, Ruschke S, Cordes C, Yap SP, Kooijman H, Hauner H, Rummeny EJ, Bauer JS, Baum T, Karampinos DC. The need for $T_{2}$ correction on MRS-based vertebral bone marrow fat quantification: implications for bone marrow fat fraction age dependence. NMR Biomed 2015;28:432-9.

58. Bingölbali A, Fallone BG, Yahya A. Comparison of optimized long echo time STEAM and PRESS proton MR spectroscopy of lipid olefinic protons at 3 Tesla. J Magn Reson Imaging 2015;41:481-6.

59. Ruschke S, Kienberger H, Baum T, Kooijman H, Settles M, Haase A, Rychlik M, Rummeny EJ, Karampinos DC. Diffusion-weighted stimulated echo acquisition mode (DW-STEAM) MR spectroscopy to measure fat unsaturation in regions with low proton-density fat fraction. Magn Reson Med 2016;75:32-41.

60. Cohen A, Shen W, Dempster DW, Zhou H, Recker RR, Lappe JM, Kepley A, Kamanda-Kosseh M, Bucovsky M, Stein EM, Nickolas TL, Shane E. Marrow adiposity assessed on transiliac crest biopsy samples correlates with noninvasive measurement of marrow adiposity by proton magnetic resonance spectroscopy ((1)H-MRS) at the spine but not the femur. Osteoporos Int 2015;26:2471-8.

61. Ren J, Dimitrov I, Sherry AD, Malloy CR. Composition of adipose tissue and marrow fat in humans by $1 \mathrm{H}$ NMR at 7 Tesla. J Lipid Res 2008;49:2055-62.

62. Karampinos DC, Melkus G, Baum T, Bauer JS, Rummeny EJ, Krug R. Bone marrow fat quantification in the presence of trabecular bone: initial comparison between water-fat imaging and single-voxel MRS. Magn Reson Med 2014;71:1158-65.

63. Kühn JP, Jahn C, Hernando D, Siegmund W, Hadlich S, Mayerle J, Pfannmöller J, Langner S, Reeder S. T1 bias in chemical shift-encoded liver fat-fraction: role of the flip angle. J Magn Reson Imaging 2014;40:875-83.

64. Arentsen L, Yagi M, Takahashi Y, Bolan PJ, White M, Yee D, Hui S. Validation of marrow fat assessment using noninvasive imaging with histologic examination of human bone samples. Bone 2015;72:118-22.

65. Schmeel FC, Vomweg T, Träber F, Gerhards A, Enkirch SJ, Faron A, Sprinkart AM, Schmeel LC, Luetkens JA, Thomas D, Kukuk GM. Proton density fat fraction MRI of vertebral bone marrow: Accuracy, repeatability, and reproducibility among readers, field strengths, and imaging platforms. J Magn Reson Imaging 2019;50:1762-72.

66. Baum T, Yap SP, Dieckmeyer M, Ruschke S, Eggers H, Kooijman H, Rummeny EJ, Bauer JS, Karampinos DC. Assessment of whole spine vertebral bone marrow fat using chemical shift-encoding based water-fat MRI: Whole Spine Water-Fat Imaging. J Magn Reson Imaging 2015;42:1018-23.

67. Baum T, Rohrmeier A, Syväri J, Diefenbach MN, Franz D, Dieckmeyer M, Scharr A, Hauner H, Ruschke S, Kirschke JS, Karampinos DC. Anatomical Variation of Age-Related Changes in Vertebral Bone Marrow Composition Using Chemical Shift Encoding-Based Water-Fat Magnetic Resonance Imaging. Front Endocrinol (Lausanne) 2018;9:141.

68. Gibbs JC, Brown ZM, Wong AKO, Craven BC, Adachi JD, Giangregorio LM. Measuring Marrow Density and Area Using Peripheral Quantitative Computed Tomography at the Tibia: Precision in Young and Older Adults and Individuals With Spinal Cord Injury. J Clin Densitom 2018;21:269-80.

69. Goodsitt MM, Hoover P, Veldee MS, Hsueh SL. The composition of bone marrow for a dual-energy quantitative computed tomography technique. A cadaver and computer simulation study. Invest Radiol 1994;29:695-704.

70. Kugel H, Jung C, Schulte O, Heindel W. Age- and sexspecific differences in the $1 \mathrm{H}$-spectrum of vertebral bone marrow. J Magn Reson Imaging 2001;13:263-8.

71. Griffith JF, Yeung DKW, Ma HT, Leung JCS, Kwok TCY, Leung PC. Bone marrow fat content in the elderly: a reversal of sex difference seen in younger subjects. J Magn Reson Imaging 2012;36:225-30.

72. Trudel G, Payne M, Mädler B, Ramachandran N, Lecompte M, Wade C, Biolo G, Blanc S, Hughson R, Bear L, Uhthoff HK. Bone marrow fat accumulation after 60 days of bed rest persisted 1 year after activities were resumed along with hemopoietic stimulation: the Women International Space Simulation for Exploration study. J Appl Physiol 2009;107:540-8.

73. Wronski TJ, Morey ER. Recovery of the rat skeleton from the adverse effects of simulated weightlessness. Metab Bone Dis Relat Res 1983;4:347-52.

74. Ahdjoudj S, Kaabeche K, Holy X, Fromigué O, Modrowski D, Zérath E, Marie PJ. Transforming growth factor-beta inhibits CCAAT/enhancer-binding protein expression and PPARgamma activity in unloaded bone marrow stromal cells. Exp Cell Res 2005;303:138-47.

75. Rantalainen T, Nikander R, Heinonen A, Cervinka T, Sievänen H, Daly RM. Differential effects of exercise on 
tibial shaft marrow density in young female athletes. J Clin Endocrinol Metab 2013;98:2037-44.

76. Casazza K, Hanks LJ, Hidalgo B, Hu HH, Affuso O. Short-term physical activity intervention decreases femoral bone marrow adipose tissue in young children: a pilot study. Bone 2012;50:23-7.

77. Styner M, Thompson WR, Galior K, Uzer G, Wu X, Kadari S, Case N, Xie Z, Sen B, Romaine A, Pagnotti GM, Rubin CT, Styner MA, Horowitz MC, Rubin J. Bone marrow fat accumulation accelerated by high fat diet is suppressed by exercise. Bone 2014;64:39-46.

78. Meunier P, Aaron J, Edouard C, Vignon G. Osteoporosis and the replacement of cell populations of the marrow by adipose tissue. A quantitative study of 84 iliac bone biopsies. Clin Orthop Relat Res 1971;80:147-54.

79. Schwartz AV, Sigurdsson S, Hue TF, Lang TF, Harris TB, Rosen CJ, Vittinghoff E, Siggeirsdottir K, Sigurdsson G, Oskarsdottir D, Shet K, Palermo L, Gudnason V, Li X. Vertebral bone marrow fat associated with lower trabecular BMD and prevalent vertebral fracture in older adults. J Clin Endocrinol Metab 2013;98:2294-300.

80. Glatt V, Canalis E, Stadmeyer L, Bouxsein ML. Age-related changes in trabecular architecture differ in female and male C57BL/6J mice. J Bone Miner Res 2007;22:1197-207.

81. Li GW, Chang SX, Fan JZ, Tian YN, Xu Z, He YM. Marrow adiposity recovery after early zoledronic acid treatment of glucocorticoid-induced bone loss in rabbits assessed by magnetic resonance spectroscopy. Bone 2013;52:668-75.

82. Shen W, Chen J, Gantz M, Punyanitya M, Heymsfield SB, Gallagher D, Albu J, Engelson E, Kotler D, PiSunyer X, Gilsanz V. MRI-measured pelvic bone marrow adipose tissue is inversely related to DXA-measured bone mineral in younger and older adults. Eur J Clin Nutr 2012;66:983-8.

83. Shen W, Chen J, Punyanitya M, Shapses S, Heshka S, Heymsfield SB. MRI-measured bone marrow adipose tissue is inversely related to DXA-measured bone mineral in Caucasian women. Osteoporos Int 2007;18:641-7.

84. Yeung DK, Griffith JF, Antonio GE, Lee FK, Woo J, Leung PC. Osteoporosis is associated with increased marrow fat content and decreased marrow fat unsaturation: a proton MR spectroscopy study. J Magn Reson Imaging 2005;22:279-85.

85. Tang GY, Lv ZW, Tang RB, Liu Y, Peng YF, Li W, Cheng YS. Evaluation of MR spectroscopy and diffusion-weighted MRI in detecting bone marrow changes in postmenopausal women with osteoporosis. Clin Radiol 2010;65:377-81.
86. Justesen J, Stenderup K, Ebbesen EN, Mosekilde L, Steiniche T, Kassem M. Adipocyte tissue volume in bone marrow is increased with aging and in patients with osteoporosis. Biogerontology 2001;2:165-71.

87. Miranda M, Pino AM, Fuenzalida K, Rosen CJ, Seitz G, Rodríguez JP. Characterization of Fatty Acid Composition in Bone Marrow Fluid From Postmenopausal Women: Modification After Hip Fracture. J Cell Biochem 2016;117:2370-6.

88. Syed FA, Oursler MJ, Hefferanm TE, Peterson JM, Riggs BL, Khosla S. Effects of estrogen therapy on bone marrow adipocytes in postmenopausal osteoporotic women. Osteoporos Int 2008;19:1323-30.

89. Duque G, Li W, Adams M, Xu S, Phipps R. Effects of risedronate on bone marrow adipocytes in postmenopausal women. Osteoporos Int 2011;22:1547-53.

90. Cohen A, Stein EM, Recker RR, Lappe JM, Dempster DW, Zhou H, Cremers S, McMahon DJ, Nickolas TL, Müller R, Zwahlen A, Young P, Stubby J, Shane E. Teriparatide for idiopathic osteoporosis in premenopausal women: a pilot study. J Clin Endocrinol Metab 2013;98:1971-81.

91. Yang Y, Luo X, Yan F, Jiang Z, Li Y, Fang C, Shen J. Effect of zoledronic acid on vertebral marrow adiposity in postmenopausal osteoporosis assessed by MR spectroscopy. Skeletal Radiol 2015;44:1499-505.

92. Di Iorgi N, Rosol M, Mittelman SD, Gilsanz V. Reciprocal relation between marrow adiposity and the amount of bone in the axial and appendicular skeleton of young adults. J Clin Endocrinol Metab 2008;93:2281-6.

93. Di Iorgi N, Mo AO, Grimm K, Wren TAL, Dorey F, Gilsanz V. Bone acquisition in healthy young females is reciprocally related to marrow adiposity. J Clin Endocrinol Metab 2010;95:2977-82.

94. Sheu Y, Amati F, Schwartz AV, Danielson ME, Li X, Boudreau R, Cauley JA; Osteoporotic Fractures in Men (MrOS) Research Group. Vertebral bone marrow fat, bone mineral density and diabetes: The Osteoporotic Fractures in Men (MrOS) study. Bone 2017;97:299-305.

95. Bredella MA, Lin E, Gerweck AV, Landa MG, Thomas BJ, Torriani M, Bouxsein ML, Miller KK. Determinants of bone microarchitecture and mechanical properties in obese men. J Clin Endocrinol Metab 2012;97:4115-22.

96. Zebaze R, Osima M, Bui M, Lukic M, Wang X, GhasemZadeh A, Eriksen EF, Vais A, Shore-Lorenti C, Ebeling PR, Seeman E, Bjørnerem Å. Adding Marrow Adiposity and Cortical Porosity to Femoral Neck Areal Bone Mineral Density Improves the Discrimination of Women 
With Nonvertebral Fractures From Controls. J Bone Miner Res 2019;34:1451-60.

97. Wren TAL, Chung SA, Dorey FJ, Bluml S, Adams GB, Gilsanz V. Bone marrow fat is inversely related to cortical bone in young and old subjects. J Clin Endocrinol Metab 2011;96:782-6.

98. Li X, Shet K, Xu K, Rodríguez JP, Pino AM, Kurhanewicz J, Schwartz A, Rosen CJ. Unsaturation level decreased in bone marrow fat of postmenopausal women with low bone density using high resolution magic angle spinning (HRMAS) 1H NMR spectroscopy. Bone 2017;105:87-92.

99. Schellinger D, Lin CS, Hatipoglu HG, Fertikh D. Potential value of vertebral proton MR spectroscopy in determining bone weakness. AJNR Am J Neuroradiol 2001;22:1620-7.

100. Schellinger D, Lin CS, Lim J, Hatipoglu HG, Pezzullo JC, Singer AJ. Bone marrow fat and bone mineral density on proton MR spectroscopy and dual-energy X-ray absorptiometry: their ratio as a new indicator of bone weakening. AJR Am J Roentgenol 2004;183:1761-5.

101.Aparisi Gómez MP, Ponti F, Mercatelli D, Gasperini C, Napoli A, Battista G, Cariani S, Marchesini G, Bazzocchi A. Correlation between DXA and laboratory parameters in normal weight, overweight, and obese patients. Nutrition 2019;61:143-50.

102.Yu EW, Greenblatt L, Eajazi A, Torriani M, Bredella MA. Marrow adipose tissue composition in adults with morbid obesity. Bone 2017;97:38-42.

103. Kim TY, Schwartz AV, Li X, Xu K, Black DM, Petrenko DM, Stewart L, Rogers SJ, Posselt AM, Carter JT, Shoback DM, Schafer AL. Bone Marrow Fat Changes After Gastric Bypass Surgery Are Associated With Loss of Bone Mass. J Bone Miner Res 2017;32:2239-47.

104. Ermetici F, Briganti S, Delnevo A, Cannaò P, Leo GD, Benedini S, Terruzzi I, Sardanelli F, Luzi L. Bone marrow fat contributes to insulin sensitivity and adiponectin secretion in premenopausal women. Endocrine 2018;59:410-8.

105. Tencerova M, Figeac F, Ditzel N, Taipaleenmäki H, Nielsen TK, Kassem M. High-Fat Diet-Induced Obesity Promotes Expansion of Bone Marrow Adipose Tissue and Impairs Skeletal Stem Cell Functions in Mice. J Bone Miner Res 2018;33:1154-65.

106. Huovinen V, Viljakainen H, Hakkarainen A, Saukkonen T, Toiviainen-Salo S, Lundbom N, Lundbom J, Mäkitie $\mathrm{O}$. Bone marrow fat unsaturation in young adults is not affected by present or childhood obesity, but increases with age: A pilot study. Metab Clin Exp 2015;64:1574-81.
107. Schafer AL, Li X, Schwartz AV, Tufts LS, Wheeler AL, Grunfeld C, Stewart L, Rogers SJ, Carter JT, Posselt AM, Black DM, Shoback DM. Changes in vertebral bone marrow fat and bone mass after gastric bypass surgery: A pilot study. Bone 2015;74:140-5.

108. Bredella MA, Greenblatt LB, Eajazi A, Torriani M, Yu EW. Effects of Roux-en-Y gastric bypass and sleeve gastrectomy on bone mineral density and marrow adipose tissue. Bone 2017;95:85-90.

109. Yu EW, Lee MP, Landon JE, Lindeman KG, Kim SC. Fracture Risk After Bariatric Surgery: Roux-en-Y Gastric Bypass Versus Adjustable Gastric Banding. J Bone Miner Res 2017;32:1229-36.

110. Franzoni E, Ciccarese F, Di Pietro E, Facchini G, Moscano F, Iero L, Monaldi A, Battista G, Bazzocchi A. Follow-up of bone mineral density and body composition in adolescents with restrictive anorexia nervosa: role of dual-energy X-ray absorptiometry. Eur J Clin Nutr 2014;68:247-52.

111. Bredella MA, Fazeli PK, Miller KK, Misra M, Torriani M, Thomas BJ, Ghomi RH, Rosen CJ, Klibanski A. Increased bone marrow fat in anorexia nervosa. J Clin Endocrinol Metab 2009;94:2129-36.

112. Bredella MA, Fazeli PK, Daley SM, Miller KK, Rosen CJ, Klibanski A, Torriani M. Marrow fat composition in anorexia nervosa. Bone 2014;66:199-204.

113. Fazeli PK, Bredella MA, Freedman L, Thomas BJ, Breggia A, Meenaghan E, Rosen CJ, Klibanski A. Marrow fat and preadipocyte factor-1 levels decrease with recovery in women with anorexia nervosa. J Bone Miner Res 2012;27:1864-71.

114.McCabe L, Zhang J, Raehtz S. Understanding the skeletal pathology of type 1 and 2 diabetes mellitus. Crit Rev Eukaryot Gene Expr 2011;21:187-206.

115. Moyer-Mileur LJ, Slater H, Jordan KC, Murray MA. IGF1 and IGF-binding proteins and bone mass, geometry, and strength: relation to metabolic control in adolescent girls with type 1 diabetes. J Bone Miner Res 2008;23:1884-91.

116. Schwartz AV, Vittinghoff E, Bauer DC, Hillier TA, Strotmeyer ES, Ensrud KE, Donaldson MG, Cauley JA, Harris TB, Koster A, Womack CR, Palermo L, Black DM; Study of Osteoporotic Fractures (SOF) Research Group; Osteoporotic Fractures in Men (MrOS) Research Group; Health, Aging, and Body Composition (Health ABC) Research Group. Association of BMD and FRAX score with risk of fracture in older adults with type 2 diabetes. JAMA 2011;305:2184-92.

117. Napoli N, Chandran M, Pierroz DD, Abrahamsen B, 
Schwartz AV, Ferrari SL; IOF Bone and Diabetes Working Group. Mechanisms of diabetes mellitus-induced bone fragility. Nat Rev Endocrinol 2017;13:208-19.

118. Machann J, Stefan N, Wagner R, Bongers M, Schleicher E, Fritsche A, Häring HU, Nikolaou K, Schick F. Intra- and interindividual variability of fatty acid unsaturation in six different human adipose tissue compartments assessed by 1 H-MRS in vivo at 3 T. NMR Biomed 2017. doi: 10.1002/ nbm.3744.

119. Lundbom J, Bierwagen A, Bodis K, Apostolopoulou M, Szendroedi J, Müssig K, Hwang JH, Roden M. 1H-MRS of femoral red and yellow bone marrow fat composition and water content in healthy young men and women at $3 \mathrm{~T}$. MAGMA 2019;32:591-7.

120.Zhu L, Xu Z, Li G, Wang Y, Li X, Shi X, Lin H, Chang S. Marrow adiposity as an indicator for insulin resistance in postmenopausal women with newly diagnosed type 2 diabetes - an investigation by chemical shift-encoded water-fat MRI. Eur J Radiol 2019;113:158-64.

121. Chen SC, Shepherd S, McMillan M, McNeilly J, Foster J, Wong SC, Robertson KJ, Ahmed SF. Skeletal Fragility and Its Clinical Determinants in Children With Type 1 Diabetes. J Clin Endocrinol Metab 2019;104:3585-94.

122. Rzonca SO, Suva LJ, Gaddy D, Montague DC, LeckaCzernik B. Bone is a target for the antidiabetic compound rosiglitazone. Endocrinology 2004;145:401-6.

123. Kahn SE, Haffner SM, Heise MA, Herman WH, Holman RR, Jones NP, Kravitz BG, Lachin JM, O'Neill MC, Zinman B, Viberti G; ADOPT Study Group. Glycemic

Cite this article as: Aparisi Gómez MP, Ayuso Benavent C, Simoni P, Aparisi F, Guglielmi G, Bazzocchi A. Fat and bone: the multiperspective analysis of a close relationship. Quant Imaging Med Surg 2020;10(8):1614-1635. doi: 10.21037/qims.2020.01.11 durability of rosiglitazone, metformin, or glyburide monotherapy. N Engl J Med 2006;355:2427-43.

124. Casamassima F, Ruggiero C, Caramella D, Tinacci E, Villari N, Ruggiero M. Hematopoietic bone marrow recovery after radiation therapy: MRI evaluation. Blood 1989;73:1677-81.

125. Cao X, Wu X, Frassica D, Yu B, Pang L, Xian L, Wan M, Lei W, Armour M, Tryggestad E, Wong J, Wen CY, Lu WW, Frassica FJ. Irradiation induces bone injury by damaging bone marrow microenvironment for stem cells. Proc Natl Acad Sci U S A 2011;108:1609-14.

126. Baxter NN, Habermann EB, Tepper JE, Durham SB, Virnig BA. Risk of pelvic fractures in older women following pelvic irradiation. JAMA 2005;294:2587-93.

127. Maddalozzo GF, Turner RT, Edwards CH, Howe KS, Widrick JJ, Rosen CJ, Iwaniec UT. Alcohol alters whole body composition, inhibits bone formation, and increases bone marrow adiposity in rats. Osteoporos Int 2009;20:1529-38.

128.Salas-Ramirez M, Tran-Gia J, Kesenheimer C, Weng AM, Kosmala A, Heidemeier A, Köstler H, Lassmann M. Quantification of fat fraction in lumbar vertebrae: correlation with age and implications for bone marrow dosimetry in molecular radiotherapy. Phys Med Biol 2018;63:025029.

129.Pichardo JC, Milner RJ, Bolch WE. MRI Measurement of Bone Marrow Cellularity for Radiation Dosimetry. J Nucl Med 2011;52:1482-9. 